Revista lus et Praxis, Año 23, № 1, 2017, pp. 511 - 554

ISSN 0717 - 2877

Universidad de Talca - Facultad de Ciencias Jurídicas y Sociales

Configuración de la prestación e incumplimiento del contrato de seguro en general

y marítimo en particular. La resolución de las controversias en torno

a la pretensión de cumplimiento específico

María Fernanda Vásquez Palma - Álvaro Vidal Olivares

Trabajo recibido el 23 de febrero de 2016 y aprobado el 24 de octubre de 2016

\title{
Configuración de la prestación e incumplimiento del contrato de seguro en general y marítimo en particular. La resolución de las controversias en torno a la pretensión de cumplimiento específico*
}

\author{
María Fernanda Vásquez Palma** \\ Álvaro Vidal Olivares ${ }^{* * *}$
}

\begin{abstract}
RESUMEN
El presente trabajo trata sobre la configuración de la prestación del asegurador en el contrato de seguro marítimo y la pretensión de cumplimiento específico para el evento de su inejecución. Los elementos de la esencia del contrato de seguro son el riesgo y la prima por su transferencia; y su efecto esencial, pero eventual para el caso que ocurra el riesgo, es la indemnización del siniestro. Esta indemnización no constituye una manifestación de la responsabilidad civil, sino el efecto que despliega este contrato a favor del asegurado y que se traduce en una obligación dineraria indeterminada cuya medida depende de la delimitación del riesgo, de su ocurrencia y la existencia de causalmente vinculados con esta última, salvo exclusión legal o contractual. La fijación de este monto debe ajustarse al principio de la reparación que rige en esta materia y a su concreción en una serie de reglas que permiten delimitar su extensión y contenido. La obligación del asegurador naturalmente comprende los llamados daños al objeto asegurado y los incidentales, no así los consecuenciales que requieren de estipulación expresa entre las partes.
\end{abstract}

\section{SUMMARY}

This paper deals with the configuration of the performance of the insurer in the contract of marine insurance and the claim for specific performance event of its non-performance. The elements of the essence of the insurance contract are the premium risk and transfer; and its essential purpose, but eventually the case that the risk occurs, is compensation for the loss. This compensation is not a manifestation of civil responsibility, but the effect displays this contract in favor of the insured and that translates into a monetary obligation whose indeterminate extent depends on the definition of the risk of occurrence and the existence of causally linked the latter, unless legal or contractual exclusion. Fixing this amount should be put out to repair governing in this matter

\footnotetext{
* Este artículo se enmarca en el Proyecto de Investigación Anillo denominado "Mecanismos alternativos de solución de conflictos como herramientas de modernización de la justicia. Construcción dogmática a partir de un análisis multidisciplinar", financiado por Conicyt Chile. SOC 1406. También en el Proyecto Fondecyt Regular № 1150511.

** Profesora de Derecho Privado de la Universidad de Talca, Doctora en Derecho por la Universidad Complutense de Madrid, correo electrónico: mfvasquez@utalca.cl.

*** Profesor Titular de Derecho Civil de la Pontificia Universidad Católica de Valparaíso, Doctor en Derecho por la Universidad Autónoma de Madrid, correo electrónico: alvaro.vidal@pucv.cl.
} 
and to its realization in a series of rules that define its scope and content. The insurer's obligation includes naturally-called insured property damage and incidental, consequential not requiring express agreement between the parties.

\author{
Palabras CLAVE \\ Contrato - seguro - riesgo - cumplimiento específico. \\ KEYWORDS \\ Contract-Insurance-Risk-Specific performance.
}

\title{
I. Introducción
}

El presente trabajo tiene por objeto presentar las particularidades de la prestación del asegurador en el contrato de seguro marítimo, delimitando los presupuestos para que ella nazca y sea exigible, junto a la pretensión de cumplimiento específico como remedio del asegurado en caso de que el asegurador infrinja el contrato.

En este camino, observaremos varios rasgos particulares del contrato de seguro en general, y del marítimo en particular, que nos llevarán a afirmar que aquí existe una estructura contractual peculiar, en tanto su objeto está representado por el riesgo asegurado que toma el nombre de "cobertura" y la contraprestación del asegurador se define como la obligación de indemnizar, que dista de la institución civil, toda vez que ella no es exigible a partir del incumplimiento contractual o de un ilícito, sino que se trata justamente de la obligación que contrae el asegurador en el contrato. En efecto, en el caso del contrato de seguro la indemnización se vincula con la determinación del objeto de la obligación que pesa sobre el asegurador, cuyo nacimiento depende de la ocurrencia del riesgo previsto por las partes y la producción de daños que sufre el asegurado en su patrimonio, causalmente vinculados con dicha ocurrencia. De esta manera, esta obligación es de dar una suma de dinero, pero de cuantía indeterminada, siendo el liquidador, el juez o el árbitro quien tiene la misión de determinarla. En base a ello, si el asegurador incumple su obligación, el asegurado podrá demandar su cumplimiento específico, lo que presupone que el sentenciador deberá determinar la suma de dinero adeuda conforme a la ley del contrato.

En pos de este objetivo, se dará respuesta a varias interrogantes. En primer lugar, ¿cómo convergen las distintas normas aplicables en juego: las contractuales civiles, las generales del contrato de seguro, y las especiales del seguro marítimo?; ¿cuál es la noción de contrato de seguros diferenciando sus elementos constitutivos, de la obligación de indemnización del asegurador?; ¿qué entendemos por riesgo, su extensión y cobertura conforme al contrato?; ¿cuándo nace la obligación de indemnizar del asegurador?; ¿cómo se fija el objeto, alcance y contenido de tal obligación?, y ¿cuándo se entiende incumplida la obligación de indemnizar y cuáles son las condiciones de procedencia de la pretensión 
de cumplimiento del contrato como principal remedio del asegurado? y ¿cómo se resuelven este tipo de conflictos?

Este ejercicio de reflexión, lo construiremos a partir de un caso, con el propósito de explicitar, a medida que se avanza en su desarrollo, las variables comprometidas e ilustrar, de manera óptima, algunos de los problemas jurídicos que pueden plantearse en la práctica. El caso nos permitirá analizar las interrogantes antes planteadas con el fin de responder a ellas de una forma dinámica.

\section{Descripción del caso, elementos y principios esenciales del contrato de seguro como contexto necesario}

\section{El caso}

Una "Sociedad de Servicios de Exportaciones Frutícolas", en adelante la "Asegurada", celebra un contrato de seguros con una Compañía, en adelante, la "Aseguradora", con el objeto de cubrir el riesgo de una fruta de exportación, almacenada en unos contenedores durante el tiempo entre su depósito en los recintos portuarios y embarque para ser transportada a destino. La Frutícola pagó una prima al Asegurador a fin de cubrir el riesgo de la fruta hasta su embarque a puerto de destino, de modo que si cualquiera de los riesgos comprendidos en la póliza tuviere lugar, procedería el pago de la indemnización en los términos convenidos.

En abril de 2015 la Exportadora tenía en el Puerto de Valparaíso 25 contenedores refrigerados con la fruta de su propiedad. Los contenedores debían ser cargados y transportados a su destino final a fines de ese mes; sin embargo, las actividades del puerto se paralizaron intempestivamente, tomando su control el sindicato de trabajadores portuarios. Tal situación se prolongó por 20 días, impidiendo el traslado, retiro y embarque de los contenedores, como, asimismo, el ingreso de los exportadores o sus dependientes a los recintos portuarios a objeto de examinar el estado de los contenedores y las mercaderías que se hallaban en su interior. Los hechos fueron calificados por la autoridad como eventos en que se utilizó la fuerza, violencia y amenazas por parte de los trabajadores, con la finalidad de ejercer presión y, de este modo, lograr sus objetivos.

Como consecuencia de lo anterior, la fruta contenida que estaba ad portas de ser embarcada y transportada, quedó retenida durante los días en que se prolongó la paralización, sufriendo un detrimento en sus atributos y calidad que, sin hacerla inservible, se tradujo en una disminución en el precio de su venta en el mercado exterior. De este modo, si bien la exportadora igualmente pudo comercializar las mercaderías, lo hizo a un menor precio que el previsto.

Ocurrido el siniestro, la Exportadora lo denunció oportunamente a la Aseguradora, la que encomendó el informe de liquidación a la empresa nominada en la póliza, que, al emitirlo, concluyó que el siniestro no estaba cubierto 
por la póliza suscrita, declarando improcedente el pago de la indemnización de los daños denunciados por la Exportadora. Según el entender del liquidador, la paralización de las labores portuarias no constituiría un riesgo cubierto por la póliza, añadiendo que el siniestro denunciado, además, se encontraría excluido por la siguiente cláusula del contrato seguro que expresa que: "toda pérdida consecuencial, incluyendo, pero no limitando a daños derivados de perjuicios por paralización, retraso, deterioro y/o pérdida de mercado, se encuentran expresamente excluidos en el contrato de seguro suscrito por las partes".

La Asegurada interpuso en contra de la Aseguradora una demanda de cumplimiento específico del contrato de seguro, junto a la correspondiente indemnización de daños. La demanda se fundó en la inejecución contractual de la aseguradora en relación a su obligación esencial de indemnizar los daños por el siniestro denunciado conforme al contrato suscrito entre las partes, en tal sentido, hace presente que, de acuerdo a la póliza, la cobertura del siniestro comprendía "La indemnización al asegurado por los valores de mercado en el evento de siniestro de daño y/o de deterioro y/o costos/gastos adicionales -por cualquier causa- comprobables de carga de fruta y vegetales, resultante de: (...) 4. Directamente de actos maliciosos y/o sabotaje y/o terrorismo sufrido por la carga cometidos por cualquier persona o personas con el propósito de causar daño económico, tanto a cualquier fruta o vegetales asegurados, como al exportador y/o relaciones comerciales entre Chile y el país importador...".

La pregunta que naturalmente emerge es si procede la cobertura del siniestro denunciado. Si la respuesta fuese afirmativa surgen nuevas interrogantes: ¿Cuáles son los fundamentos y los medios para solicitar el cumplimiento específico de este contrato? y ¿en qué se traduce tal cumplimiento? Para brindar respuesta a aquéllas debemos configurar y comprender la prestación comprometida por la Aseguradora, junto al contenido y condiciones de procedencia de la pretensión de cumplimiento específico. Nos encontramos, como podemos advertir, en terreno del seguro de daños, de manera que delimitaremos nuestro estudio en esa dirección.

\section{El concepto de contrato de seguro}

En la doctrina se ofrecen varias definiciones del contrato de seguro, entre ellas destacamos la de Sánchez Calero que lo concibe como "El contrato por el cual el asegurador, mediante la percepción de una prima, se obliga frente al asegurado al pago de una indemnización, dentro de los límites pactados, si se produce el evento previsto" ; y la de Broseta Pont, quien asevera que "el seguro

1 SÁNCHeZ (2009), p. 489. 
es un contrato por el cual el asegurador, contra la percepción de una prima, se obliga a indemnizar o a reparar al asegurado, dentro de los límites convenidos, el daño producido por el siniestro, o a pagar un capital o una renta a la realización de un evento o suceso que afecte la vida humana" ${ }^{2}$. En ambas construcciones dogmáticas se pone acento en el riesgo y en la indemnización del daño que sufriere el asegurado, cuya extensión -a diferencia de aquella que es objeto de la responsabilidad civil-siempre queda sujeta a la voluntad anticipada de las partes, limitación que-como se explicará- está estrechamente relacionada con la medida del riesgo asegurado. Siguiendo este derrotero, nuestro Código de Comercio, en su artículo $512^{3}$, ofrece una definición descriptiva, expresando que: "Por el contrato de seguro se transfieren al asegurador uno o más riesgos a cambio del pago de una prima, quedando éste obligado a indemnizar el daño que sufriere el asegurado, o a satisfacer un capital, una renta u otras prestaciones pactadas. Los riesgos pueden referirse a bienes determinados, al derecho a exigir ciertas prestaciones, al patrimonio como un todo y a la vida, salud e integridad física o intelectual de un individuo (...)".

De lo expuesto podemos decir que el contrato de seguro es aquel por el cual una parte -denominada asegurada- transfiere a otra -el asegurador- un riesgo previsto en el contrato, obligándose el asegurado al pago de una prima -el precio-y el asegurador al pago de la indemnización pactada, en caso de la ocurrencia de tal riesgo ${ }^{4}$. En este contexto, los elementos de la esencia de este contrato son el riesgo y la prima; y uno de sus efectos esenciales -pero eventual para el caso que ocurra el riesgo previsto- es la obligación de indemnizar al asegurado según lo pactado.

Una de las clasificaciones del seguro atiende al lugar donde los riesgos que se transfieren al asegurador acaecen y amenazan las cosas, personas o derechos objeto del contrato. Así se distinguen entre seguros terrestres, marítimos y

\footnotetext{
2 Broseta (1991), p. 529.

3 Modificado a partir de la ley No 20.667, de mayo de 2013.

4 "Este contrato se caracteriza por ser consensual en términos que su existencia y estipulaciones podrán acreditarse por todos los medios de prueba que contemplen las leyes, siempre que exista un principio de prueba por escrito que emane de cualquier documento que conste en télex, fax, mensajes de correo electrónico y, en general, cualquier sistema de transmisión y registro digital o electrónico de la palabra escrita o verbal" (art. 515 Código del Comercio). Es bilateral, de manera que genera obligaciones recíprocas para ambas partes, el asegurado está obligado a pagar la prima y el asegurador debe indemnizar al asegurado una vez que suceda el siniestro (art. 529 del Código de Comercio); aleatorio, generalmente es de adhesión, pues sus cláusulas, especialmente aquéllas denominadas condiciones generales, corresponden a textos impresos predispuestos, aplicables a todos los contratos del mismo ramo. Finalmente, es dirigido y, normalmente, es individual. Véase: VeIGA (2014), pp. 110-170.
} 
aéreos ${ }^{5}$. El seguro marítimo se podría definir como aquél en virtud del cual un asegurador toma sobre sí el todo o parte de los riesgos originados en el transporte marítimo que pueda afectar a la nave o a la carga, o a los intereses económicos que de allí se derivan, mediante el pago de una retribución convenida, a cargo del asegurado, que se denomina prima ${ }^{6}$. Complementando ello, debe señalarse que el seguro marítimo cubre los riesgos de navegación marítima, concepto que se entiende más amplio que el transporte marítimo, toda vez que no toda navegación implica transporte, como sucede, por ejemplo, con los remolcadores, naves pesqueras, naves de investigación científica, artefactos navales, etc. Por otra parte, habría que incorporar las coberturas de seguros que proporcionan los Clubes de Protección e Indemnización, organizados en base a mutualidades ${ }^{7}$. De acuerdo al art. 1161 del Código de Comercio chileno prescribe que "Por regla general, los seguros marítimos tienen por objeto indemnizar al asegurado respecto de la pérdida o daño que pueda sufrir la cosa asegurada por los riesgos que implica una aventura marítima, fluvial, lacustre, o en canales interiores", en base a ello, se podría señalar que este tipo de seguro se refiere a una institución jurídica que tiene por objeto la transferencia de un riesgo de pérdida, daño, gasto o responsabilidad propio de la navegación marítima, fluvial, lacustre o en canales interiores, a cambio de una retribución económica ${ }^{8}$. De este modo, el seguro marítimo es un tipo especial de seguro, cuya particularidad deriva del lugar y actividad donde acontecen los riesgos, esto es, navegación marítima. La nota particular de este seguro proviene de los riesgos o peligros de navegación, que aluden a la aventura marítima en una noción amplia.

El art. 1161 antes relatado, debe interpretarse en concordancia con lo dispuesto en el art. 1163, según el cual, además de los riesgos señalados en el artículo anterior, las partes pueden agregar al contrato de seguro otros riesgos que pueda correr la cosa asegurada, ya sea durante su permanencia en puerto, dique, mar, ríos, lagos y canales, cuando se trate de una nave, o mientras aquéllas estén en tránsito por otros medios de transporte o en depósito antes o después de la expedición marítima. En otros términos, la expedición marítima se inicia, transita o concluye en alguna de estas formas de navegación o en tierra, constituyendo este segmento parte de la aventura ${ }^{9}$.

\footnotetext{
${ }^{5}$ Véase Baeza (1994), p. 35; Barroilhet (2007), p. 24.

${ }^{6}$ AnSiETA (1976), p. 11.

7 Barrollhet (2007), p. 24.

${ }^{8}$ Barrollhet (2007), p. 26.

${ }^{9}$ De acuerdo al art. 1160 del CCo. Los seguros marítimos pueden versar sobre: 1 . Una nave o artefacto naval, sus accesorios y objetos fijos o móviles, cualquiera sea el lugar en que se encuentren, incluso en construcción; 2. Mercancías o cualquier otra clase de bienes que puedan sufrir riesgos de transporte
} 
Ahora bien, el seguro marítimo tiene por objeto indemnizar al asegurado la pérdida o daño que pueda sufrir la cosa asegurada por los riesgos que implica una aventura marítima, fluvial, lacustre o en canales interiores. Se encuentra normado en el título VII del Libro III del Código de Comercio, siendo complementada, en forma supletoria, por las normas generales del referido cuerpo legal (art. 1158 Código de Comercio). Tal régimen se caracteriza porque, a menos que las normas sean expresamente imperativas, éstas son disponibles para las partes, privilegiando la autonomía privada ${ }^{10}$. Así se desprende del artículo art. 1159 del Código de Comercio, norma que constituye una excepción al artículo 542 del mismo cuerpo legal que, por el contrario, asigna carácter imperativo e indisponible a la generalidad de la normativa sobre seguros ${ }^{11}$, salvo tratándose del contrato cuyo objeto sean grandes riesgos ${ }^{12}$.

En tal sentido, frente al caso en análisis debemos aplicar el acuerdo fruto de la autonomía privada de las partes. A falta de estipulaciones expresas, se regirá por las normas que conforman el régimen especial del seguro marítimo; $y$, en caso de laguna en este último, por las generales de los artículos 512 y siguientes del Código de Comercio, que constituyen el derecho común y supletorio en la materia. Adicionalmente, en lo no previsto por las partes y el Código de Comercio, este contrato se rige por las reglas generales del Libro IV del Código $\mathrm{Civil}^{13}$. Esta conjunción normativa presenta un rico sustrato de normas aplicables que corresponde develar de acuerdo al caso concreto.

\section{La buena fe y la reparación como principios generales que contribuyen a la configuración del contenido obligacional del contrato}

En el contrato de seguro rige el principio de buena fe-entendida como regla de lealtad de trato, rectitud de intención, honorabilidad comercial y de actuar

marítimo, fluvial o lacustre; 3. El valor del flete y de los desembolsos en que incurra quien organiza una expedición marítima, o 4. La responsabilidad de una nave u otro objeto, por los perjuicios que puedan resultar frente a terceros como consecuencia de su uso o navegación".

10 La ventaja de esta configuración reside en que la norma pueda resistir a los cambios y así adaptarse de mejor forma a la actualización de los contratos y laudos arbitrales. Véase informe técnico de la Comisión Redactora del Libro Tercero del Código de Comercio, p. 47.

11 Ríos (2015 b), p. 350.

12 Sobre el cambio introducido por la ley $N^{\circ} 20.667$ en cuanto al carácter imperativo de las normas generales sobre seguros, véase: http://www.svs.cl/educa/600/w3-article-13977.html. Las nuevas normas contenidas en el Código tienen carácter imperativo (obligatorias), salvo que en el contrato se estipulen condiciones más beneficiosas para el asegurado.

13 En general para los contratos, véase: VIDAL (2000), pp. 213-219. 
exento de todo propósito de perjudicar al otro contratante- ${ }^{14}$, de una forma particular, pues las partes no sólo quedan sujetas al deber general que impone el artículo 1546 del Código Civil, sino que el régimen legal del contrato de seguro les impone un deber adicional referido al máximo deber de lealtad con concreciones normativas expresas ${ }^{15}$, de este modo, la buena fe no sólo actúa como principio ${ }^{16}$, también se trata de una norma de conducta esperable. En este contexto, la ley impone al asegurado el deber de brindar al asegurador una información veraz y completa respecto de los riesgos que desea asegurar (artículo $524 \mathrm{~N}^{0} 1$ CCo. $)^{17}$ y, en la aseguradora, el deber de ofrecer coberturas que esté en condiciones de cumplir y que, en todo caso, sean útiles a las necesidades del asegurado (artículo 529 № 1 Código de Comercio). Por su parte, al asegurador le está vedado ofrecer al asegurado un seguro cuya aplicación resulte dificultosa; emitir una póliza expresada en términos ambiguos; ni entregar, previo a la celebración del contrato, informaciones que induzcan a error al asegurado.

También inspirado en el mismo principio y yendo en la misma dirección, el artículo $524 \mathrm{~N}^{0} 4$ del Código de Comercio ${ }^{18}$, impone al asegurado -a pesar de ser víctima del siniestro y titular del derecho a la indemnización- el deber de mitigar los daños subsecuentes de tal siniestro y, al mismo tiempo, obliga al asegurador a reparar los gastos que tal mitigación implique al asegurado (costes o daños incidentales). Ya volveremos sobre esta carga y su incidencia en la extensión de la indemnización ${ }^{19}$.

\footnotetext{
${ }^{14}$ En un intento de sistematizar este principio, el profesor Díez-Picazo identifica específicas manifestaciones de la buena fe que permiten realizar un test para averiguar si la conducta se ha ajustado o no a ese deber ético de comportamiento. Véase: Dírz-Picazo (2008), $6^{a}$ ed., p. 500; y véase: López (2010), pp. 348-360.

15 Así aparece en: Barrientos (2015 b), pp. 423-451; y en Barrientos (2015 a), pp. 65-104.

${ }^{16}$ Como principio se proyecta a todo el iter contractual y actúa tres funciones: constituye un dispositivo de interpretación contractual, actúa como fuente de deberes para el deudor y acreedor y protege la razonable confianza creada por las partes en todas las fases de la vida del contrato. Véase: LópEz (2010), p. 347.

17 Sobre este tema, véase: BarRientos (2015 c).

18 Sobre este tema, véase: Lagos (2015).

${ }^{19}$ En aquellos ordenamientos en los que no se reconoce con el carácter general las cargas de mitigar las pérdidas, la doctrina la sostiene fundándola en la buena fe objetiva. En España: Dífz-PICAzo y PONCE DE León (2008), han señalado que: "Hay, ante todo un deber de la buena fe de evitar la extensión de los daños, adoptando para ello las precauciones que la razonable diligencia exige". En Chile: (Domínguez (2005), p. 89; VIDAL (2008), pp. 450-451). En contra de esta tesis: PizArRo (2013) asevera que el argumento más adecuado para justificar el deber de minimizar el daño, consiste en la causalidad, pues como lo señala el artículo 1558 CC, el deudor es sólo responsable de los daños que son una consecuencia directa e inmediata de su incumplimiento, salvo la hipótesis de infracción dolosa.
} 
Ahora bien, la finalidad última del contrato de seguros es la indemnización del asegurado respecto de aquellas pérdidas provenientes de la eventual realización del riesgo cubierto por la póliza, riesgo constitutivo de sucesos o eventos cuya ocurrencia afecta económicamente al asegurado. El artículo 550 del Código de Comercio recoge este principio rector al disponer que: "Respecto del asegurado, el seguro de daños es un contrato de mera indemnización y jamás puede constituir para él la oportunidad de una ganancia o enriquecimiento" ${ }^{20}$. Se excluye expresamente la contingencia de ganancia, porque la finalidad de la ejecución del seguro es el restablecimiento de la integridad patrimonial del asegurado mediante la reparación de los daños que efectivamente le irrogó el siniestro y que correspondan al riesgo transferido al asegurador. La base de este principio se encuentra en el interés equivalente a la intención positiva del asegurado que el siniestro no ocurra y el daño no se configure (interés asegurable) ${ }^{21}$. De este modo, este principio debe leerse en términos que de ocurrir el riesgo transferido al asegurador, éste queda obligado a indemnizar al asegurado aquellos daños efectivamente ocurridos y vinculados causalmente con tal riesgo, situándole en la misma posición como si el siniestro no hubiera tenido lugar.

Miradas las cosas de este modo, este contrato tiene como finalidad el resguardo de la estabilidad económica desde un punto de vista general y particular. La extensión de la indemnización dependerá del riesgo transferido al asegurador, considerando las exclusiones que la póliza prevea, de manera que cuando afirmamos que por el contrato el asegurador se obliga a la indemnización convenida, aludimos a que ella siempre está limitada a los daños provenientes del riesgo cubiertos por la póliza y no a otros, aunque efectivamente el asegurado los hubiese experimentado. Esta es la particularidad del contrato en análisis, pues aquí no rige el principio de la reparación integral, propio y característico de la responsabilidad civil extracontractual, de acuerdo al artículo 2329 del Código Civil22, sino la reparación de aquellos daños cubiertos por la póliza. El límite de esta indemnización proviene de la voluntad de las partes.

\footnotetext{
${ }^{20}$ La aplicación de esta regla calza con el seguro de daños; sin embargo, puede alterarse o hacerse excepción al mismo cuando se pacte entre los contratantes un seguro a valor convenido (artículo 554 del Código de Comercio) o un seguro a valor de reposición (artículo 555 del Código de Comercio).

21 El principio de la reparación encuentra reconocimiento en otras disposiciones de este título, como aquella que dispone que la suma asegurada constituye el límite de la indemnización (art. 552); la que regula la valoración del bien asegurado (art. 554), y la que regula la existencia de pluralidad de seguros (art. 556).

22 Barros (2007) afirma y justifica este principio sin limitaciones tratándose del daño patrimonial y que se traduce en el derecho de la víctima a ser restituida a la situación patrimonial que tendría si no hubiese sufrido el daño.
} 
Adicionalmente se excluirán de la indemnización aquellos daños que el asegurado podría razonablemente haber evitado, en base a las exigencias de la buena $\mathrm{fe}^{23}$, toda vez que los referidos daños no provinieron inmediatamente del siniestro en cuestión, sino que de la omisión del asegurado, de manera que la reducción se explica en la causalidad. Entender las cosas de otra forma implicaría vulnerar no sólo el principio de la causalidad, sino también el de la buena fe objetiva. Más abajo ilustraremos acerca de cómo operaría la regla recurriendo al caso.

\section{El riesgo y la causalidad como elemento de la esencia del contrato de seguros. Ribetes de trascendencia para la configuración de la prestación}

Asumiendo que el riesgo es un elemento esencial del contrato de seguro, debemos detenernos en su definición, esto es: "La eventualidad de un suceso que ocasione al asegurado o beneficiario una pérdida o una necesidad susceptible de estimarse en dinero" (art. 513, t) Cco.). En el seguro marítimo, puede definirse como la posibilidad que ocurra un evento marítimo extraordinario y dañino para el patrimonio del asegurado. Sus elementos esenciales son: hecho posible de ocurrir; extraordinario; dañino, marítimo o relacionado a la navegación ${ }^{24}$. El art. 1161 del Cco. prescribe que, por regla general, los seguros marítimos tienen por objeto indemnizar al asegurado respecto de la pérdida o daño que pueda sufrir la cosa asegurada por los riesgos que implica una aventura marítima, fluvial, lacustre, o en canales interiores, de manera que conecta los riesgos que son inherentes a la aventura marítima.

De faltar este elemento constitutivo esencial, el contrato de seguro adolecería de nulidad absoluta según lo dispuesto por el artículo 521 del Código de Comercio. Como se advierte de la definición, el riesgo se caracteriza por la eventualidad de que algo puede suceder o no, siendo improcedente hablar de riesgo cuando la ocurrencia del evento o suceso sea imposible o absolutamente cierta. Para que nazca la obligación de indemnizar, el riesgo, además de ser incierto, debe ser ajeno a la voluntad del propio asegurado.

El riesgo que asume el asegurador obedece a un proceso que comprende dos fases: una técnica, que efectúa el asegurador en cuanto empresa, valorando las probabilidades de acuerdo a ciertos criterios; y otra jurídica, en la que se

\footnotetext{
${ }^{23}$ Justificando no la existencia del deber o carga de mitigar las pérdidas, sino las consecuencias de su infracción en la causalidad según el artículo 1558 del Código Civil: VIDAL (2008), p. 451. Por su parte, Pizarro (2013), p. 78, entiende que la justificación de la exclusión o rebaja de la indemnización se hallaría en la regla de la previsibilidad, o más bien, en que las pérdidas razonablemente evitables no serían previsibles para el deudor al tiempo del contrato.
}

${ }^{24}$ Barroilhet (2008), p. 150. 
individualiza y delimita sus probabilidades. El evento de peligro susceptible de ser asegurado debe estar detalladamente descrito en el contrato (artículo 530 Código de Comercio), de modo que se establezca claramente en qué consiste (ej. riesgo de incendio, de robo, responsabilidad civil, etc.). Esta descripción puede hacerla el legislador o las partes, la legislativa representa la individualización genérica del riesgo asegurable y apunta a garantizar una cobertura mínima, evitando que en el contrato se incorporen exclusiones que la hagan inoperante; en cambio, la convencional contiene los condicionados particulares de la póliza que las partes incorporen. Junto con la delimitación del riesgo, determinando sus causas, espacios y temporalidad, se suma el quantum de la prestación del asegurado, que, en definitiva, determinará la extensión de su obligación indemnizatoria ${ }^{25}$.

Ahora bien, de acuerdo al artículo 530 del Código de Comercio, "El asegurador responde de los riesgos descritos en la póliza, con excepción de las situaciones expresamente excluidas por ella. A falta de estipulación, el asegurador responde de todos los riesgos que por su naturaleza correspondan, salvo los excluidos por la ley". Para el caso del seguro marítimo, la aventura y su extensión dependen de lo que las partes estipulen en el contrato de seguros; no obstante, a falta de estipulación en contrario, se entienden incluidos en el riesgo los peligros que provengan o puedan ocurrir como consecuencia de la navegación o de estar la nave o artefacto naval en puerto o detenidos, incluyendo en este concepto los peligros derivados de las condiciones del tiempo, incendio, piratas, ladrones, asaltantes, capturas, naufragios, varamientos, abordajes, cambios forzados de ruta, apresamiento, saqueo, requisamiento por orden de autoridad administrativa, retención por orden de policía extranjera, represalia $y$, en general, todos los casos fortuitos que ocurran en el mar u otros medios. Cualquier excepción a estos riesgos, deberá constar en la póliza (art. 1162 CCo.). Además de estos riesgos, las partes pueden agregar al contrato de seguro otros riesgos que pueda correr la cosa asegurada, ya sea durante la permanencia en puerto, dique, mar, ríos, lagos y canales o, cuando no se trate de una nave, mientras aquélla se encuentre en tránsito por otros medios de transporte o en depósito antes o después de una expedición marítima (art. 1163).

Si se realiza alguno de estos riesgos quiere decir que ha tenido lugar el siniestro, activándose la obligación de indemnizar del asegurador. En tal entendido, debemos considerar que no siempre la realización de un riesgo impone al asegurador la obligación de indemnizar al asegurado, toda vez que debemos atender a la causa de su ocurrencia, considerando que la propia noción de riesgo o la voluntad de las partes pueden excluir ciertas posibilidades para provocar

${ }^{25}$ Véase: Ríos (2015 a), p. 160. 
este efecto contractual, de manera que, a pesar de la realización del riesgo y el daño, no tendrá lugar la indemnización.

La causalidad precisa analizar las circunstancias de hecho que explican fácticamente el origen del daño, análisis que ha de conducir a determinar la causa que originó el siniestro a objeto de definir si ella está o no cubierta por el seguro. El examen de la relación de causalidad en este contrato apunta a dilucidar principalmente si un siniestro encuentra o no cobertura en aquellos casos en que en su ocurrencia confluyan más de una causa. No estamos situados en la causalidad propia de la responsabilidad civil, sino en un terreno más estrecho, esto es, aquel que refiere al daño cuya indemnización reclama el asegurado y su conexión causal con un riesgo o evento cubierto por el contrato del seguro.

Sobre esta materia, la doctrina prevalente en Chile postula la solución de la causa adecuada que nos enseña que la causa del daño será aquella que, según el curso normal de los acontecimientos y la apreciación de un observador externo, resulta adecuada y suficiente para producirlo ${ }^{26}$. Tal como afirma Barros, de acuerdo a la formulación más tradicional de la doctrina de la causa adecuada, la imputación de daños consecuentes sólo se justifica si desde la perspectiva de un observador experimentado, que mira retrospectivamente la cadena causal, tales daños no resultan inverosímiles; añadiendo que la adecuación se muestra en que el hecho culpable es apropiado, bajo el curso ordinario y no extravagante de los acontecimientos, para producir las consecuencias dañosas ${ }^{27}$.

El criterio de imputación de daños es el de la previsibilidad objetiva develada retrospectivamente, entendiéndose que conforme a ella, el resultado dañoso vinculado causalmente, en este caso con el siniestro que lo irroga, ha de ser una consecuencia natural u ordinaria del mismo y, en ese entendido, adecuada y suficiente para producirlo. Será así cuando entre el acto o hecho inicial y el daño exista una necesaria relación de acuerdo a los conocimientos atribuidos a aquel observador externo, debiendo ponderarse si tal acto o hecho que se presenta como causa, tiene la aptitud suficiente para que de él se derive -como una consecuencia necesaria- el efecto lesivo que se arroja como resultado. En general será posible aislar e identificar por el sentenciador la causa adecuada de la cadena de circunstancias que condujeron al daño reclamado, excluyendo las restantes ${ }^{28}$.

\footnotetext{
${ }^{26}$ Contreras (2014), pp. 109 y ss.

27 Barros (2007), p. 396.

28 Por esta razón, BarRos (2007), p. 396. Afirma que esta doctrina de la causa adecuada no representa un criterio que defina positivamente cuáles consecuencias deben ser considerados como daños atribuibles al acto o hecho de que se trate, sino que establece condiciones negativas para excluir la responsabilidad cuando los acontecimientos se desencadenan en un curso causal anormal o extraordinario, ajeno al impuesto por el hecho negligente.
} 
Ahora bien, si la pérdida o daño de la cosa asegurada proviene de varias causas, el asegurador será responsable sólo si la causa principal o determinante es un riesgo cubierto por la póliza. En el caso que no fuere posible establecer esta última, o si varias causas determinantes fueron simultáneas y entre ellas hubiera una constitutiva de un riesgo asegurado, el asegurador será responsable por el daño en los términos expresados por la póliza (art. 1184 CCo.) En este punto el seguro marítimo toma distancia del régimen general dado que conforme el artículo 533 del Código de Comercio, habiendo pluralidad de causas, el asegurador será responsable del siniestro si cualquiera de las causas concurrentes corresponde a un riesgo cubierto por la póliza. En este último caso, la norma parece fundarse en una mayor protección del asegurado.

Vistas las normas sobre causalidad, procede detenernos en aquellas que rigen la cobertura. En este orden de ideas, debemos recordar que en el seguro marítimo, existen riesgos se encuentran "naturalmente" cubiertos, salvo las estipulaciones de las partes en sentido diverso "los peligros que provengan o que puedan ocurrir como consecuencia de la navegación o de estar la nave o artefacto naval en puerto o detenidos, incluyendo en este concepto, los peligros derivados de las condiciones del tiempo, incendio, piratas, ladrones, asaltantes, capturas, naufragios, apresamientos, saqueo, requisamiento por orden de la autoridad administrativa, retención por orden de potencia extranjera, represalia $y$, en general, todos los casos fortuitos que ocurran en el mar u otros medios ${ }^{\prime 29}$. En base a ello, cualquiera exclusión de los riesgos descritos supletoriamente por la norma, deberá constar expresamente en la póliza dando cuenta del acuerdo de voluntad entre las partes en este sentido ${ }^{30}$.

De este modo, el seguro cubre todos los riesgos descritos por la póliza, que en materia de seguro marítimo, salvo estipulación en contrario, comprenden a todos aquellos que describe supletoriamente el artículo 1160 Código de Comercio $^{31}$. Adicionalmente, según el artículo 535 del citado Código, el

\footnotetext{
${ }^{29}$ Sobre el contenido de estos riesgos, véase: Barroilhet (2008), pp. 159 y ss.

30 Esta regla puede mirarse como una concreción del artículo 530 del Código de Comercio que dispone que a falta de estipulación en sentido diverso, el asegurador responde por la ocurrencia de todos los riesgos que por su naturaleza correspondan y para comprender el sentido de esta última expresión es conveniente recurrir al antiguo y derogado artículo 539 del Código de Comercio que recogía la misma regla y que era entendida en términos que, ante la ausencia de pacto entre las partes, el seguro cubría todos los riesgos que correspondan a la familia o ramo de riesgos a que pertenezca la póliza. Véase: CONTRERAS (2014), p. 506.

31 De acuerdo al art. 1174 del Cco. "En el seguro sobre mercancías o carga, no será necesaria la individualización precisa del asegurado, pudiendo concretarse éste por cuenta de quien corresponda y la analizamos al tratar al asegurado de este tipo de coberturas. Por otra parte, cuando se trate de seguro de naves y éste no estuviere contratado por su dueño, el asegurador deberá consignar en la póliza la relación o interés asegurable que exista entre la persona a cuyo favor se extiende la póliza y la nave
} 
asegurador también toma sobre sí, aun sin mención expresa, todos los riesgos descritos en la póliza cuya causa sean eventos de caso fortuito, incluyéndose los que provengan de culpa o dolo de terceros e incluso aquellos atribuibles a la culpa leve del asegurado. Esta última regla que integra el contrato de seguro debe entenderse sin perjuicio del acuerdo de las partes.

Adicionalmente, el asegurador responde por las pérdidas o daños de los objetos asegurados que provengan de culpa o dolo del capitán o tripulación. Por otro lado, si las partes nada acuerdan en la póliza, esta clase de seguro excluye el riesgo de demora. Más allá de ello, las partes son libres para convenir que el seguro se extienda a otros riesgos a los que pueda estar expuesta la cosa asegurada, ya sea durante la permanencia en el puerto, dique, mar, ríos, lagos y canales, o cuando se trate de una nave, como el caso de las mercancías, mientras se encuentran en tránsito por otros medios de transporte o en depósito antes o después de una expedición marítima.

En cuanto a los riesgos excluidos, de acuerdo al art. 1181, el asegurador es responsable por la pérdida o daño de los objetos asegurados que provengan de culpa o dolo del capitán o de la tripulación, pero no será indemnizada la pérdida o daño al casco que provenga de dolo del capitán, salvo estipulación expresa. En este punto, se debe tener presente que respecto de los hechos culposos del asegurado y sus dependientes, ambos son objetos de seguro, de hecho, una de las coberturas típicas reguladas en el art. $1160 \mathrm{~N}^{\circ} 4$ del Cco, es el seguro de responsabilidad. Por su parte, de acuerdo al art. 1182, el asegurador no será responsable por pérdidas causadas por demora, aun cuando ésta tuviere su origen en un riesgo cubierto por la póliza, a menos que expresamente así se estipule. Asimismo, salvo pacto en contrario, el asegurador no es responsable por los fenómenos ordinarios de filtración, rotura o desgaste, por vicio propio o de la naturaleza de la cosa asegurada y otros normales del transporte (art. 1183 CCo.). De este modo, en cada póliza se regula esta materia de forma específica, debiendo considerar para ello sus distintos tipos, y si ello no ocurre, rige lo señalado por la ley.

Trasladémonos nuevamente a nuestro caso.

El detrimento en la calidad de la fruta y su consiguiente disminución del precio de venta en el mercado externo, tendría dos causas; a saber: (a) la paralización o huelga ilegal de los trabajadores portuarios y la re-

que se asegura. Esta norma es propia de la cobertura de casco y obliga a individualizar al asegurado que no es propietario de la nave asegurada y señalar en qué consiste su interés asegurable. La omisión de esta indicación hace presumir que el asegurado es su propietario. En relación a los tipos de pólizas, existen numerosos modelos de seguros marítimos incorporados a depósito, incluyendo póliza de cascos (por tiempo o por viaje), póliza de transporte de mercancías; póliza de contenedores, pólizas de responsabilidad civil para fletadores, operadores de terminales marítimos, estibadores y astilleros constructores y reparadores, pólizas de piscicultura, etc. Véase: BARROILHET (2007), pp. 419 y ss. 
tención de los contenedores; y (b) la consiguiente demora en el retiro y embarque de estos últimos para la venta posterior de la fruta contenida en ellos. Desde un punto de vista natural habría pluralidad de causas, la primera cubierta por la póliza, y otra excluida, la demora. Entonces, para develar si el asegurador, resulta o no obligado a la indemnización, necesariamente debe despejarse la causa del daño. Para tal fin conviene aplicar la regla del artículo 1184 del Código de Comercio que ordena estar a la causa principal del daño de modo que si ella coincide con un riesgo previsto por el contrato, el asegurado tendría derecho a la indemnización. Aquí se puede observar que la causa principal, adecuada y suficiente del detrimento a las mercaderías y su disminución de valor en el mercado, fue la paralización o huelga ilegal y la consiguiente retención de las mercaderías -riesgo cubierto por la póliza-; y no la demora, que fue una consecuencia del hecho precedente y no la causa principal del daño a la fruta. Entonces, aun cuando en este caso estimemos que hay pluralidad de causas, si aplicamos la norma citada, el conflicto se resuelve a favor del asegurado, activándose la obligación de indemnización.

Vale la pena subrayar que el riesgo que invoca la demandante como fundamento de su demanda no es la demora en la entrega de los productos ${ }^{32}$, sino los actos de terceros realizados con expreso ánimo de causar un daño económico a la carga de los contenedores existentes en los recintos portuarios, lo que obedeció a la presión que querían ejercer para obtener éxito en sus demandas. Al retener las mercaderías, los huelguistas ilegales sabían o debían saber, que su conducta provocaría un daño en aquéllas, más tratándose de mercaderías perecibles como es el caso de la fruta fresca de exportación. En este entendido, podríamos sostener que se trató de actos maliciosos y de sabotaje, entendidos en su noción amplia. El dolo de los huelguistas no se infirió en contra la Asegurada, sino respecto del sistema portuario, al utilizar esta herramienta (retención o apresamiento de mercaderías como medida de coacción), a sabiendas de sus efectos. Este hecho de terceros, aun cuando hubiese sido realizado con culpa -en este caso, al menos grave-, se asimila al caso fortuito que es un riesgo cubierto en el contrato de seguros de manera general.

En otras palabras, en el caso la demora fue ajena la voluntad del asegurado, se trató de una retención de cargamento por parte de terceros

32 Que dispone: "Toda pérdida consecuencial, incluyendo, pero no limitando a daños derivados de perjuicios por paralización, retraso, deterioro y/o pérdida de mercado, se encuentran expresamente excluidos en el contrato de seguro suscrito por las partes". 
partícipes de una huelga ilegal, de modo que mal podría aplicarse el razonamiento del citado artículo 1182 del Código de Comercio. Dadas las características de estos hechos, deben verse como caso fortuito.

\section{Reglas probatorias: un cambio de paradigma}

En cuanto a la ocurrencia del siniestro es insoslayable la prueba de si el asegurador es o no responsable por el evento dañoso (artículo 531), la época en que tuvo lugar (artículo 532), y la concurrencia de pluralidad de causas (artículo 533). En lo que concierne al primero de los puntos, según el citado artículo 531, el siniestro se presume ocurrido por un hecho o evento que hace responsable al asegurador, es a éste a quien le corresponderá probar lo contrario. En el mismo sentido, de acuerdo al artículo 1185 del mismo Código, en relación al seguro marítimo, corresponderá al asegurador el peso de probar que el siniestro ha ocurrido por un hecho o riesgo no comprendido en la póliza. Ambas disposiciones contienen la misma regla pero formulada desde ángulos diversos, la primera establece la presunción y envuelve implícitamente la asignación de la carga de la prueba; la segunda, en cambio, explicita dicha asignación, permitiendo la construcción de una presunción de cobertura de riesgo. Para ambas es al asegurador a quien le corresponde la carga de excluir el siniestro de la cobertura en términos que, mientras no lo logre, queda obligado al pago de la respectiva indemnización.

Como se puede observar, la presunción se establece en favor del asegurado, lo que se traduce en entender que el evento notificado al asegurador como siniestro, ha sido provocado por una causa prevista en el contrato, de modo que queda dentro de la delimitación causal del riesgo según la póliza. A partir de ello, advertimos en esta materia una excepción a la regla general sobre el onus probandi del artículo 1698 del CC que distribuye las cargas probatorias de la existencia y extinción de las obligaciones. En efecto, al tenor de las dos disposiciones legales comentadas, al asegurado le bastaría con probar la existencia del contrato y la ocurrencia del siniestro cubierto en la póliza. De no mediar esta última prueba, el asegurador queda obligado y el asegurado tiene el derecho correlativo a la indemnización conforme el contrato de seguros. Se ha entendido que esta presunción encuentra su respaldo en el principio de la buena fe, así como en el supuesto de veracidad e integridad de la información entregada, tanto al traspasar el riesgo, como al dar cuenta del evento dañoso y sus circunstancias ${ }^{33}$.

33 Arellano (2013), p. 263. 
El antecedente de esta regla se encuentra en la norma anterior a la vigencia de la reforma de la ley $N^{\circ}$ 20.667, que presumía la ocurrencia del siniestro por caso fortuito, nomenclatura que hoy está obsoleta en materias de seguros al presentar una mirada restrictiva respecto de la causalidad, y difícil de conciliar con las normas de indemnización contempladas en materia civil, pues esta última no emerge sólo del caso fortuito.

Volvamos al caso y analicemos la cobertura del contrato:

La póliza, en uno de sus numerales, expresa, al fijar su cobertura, que: ella comprende "La indemnización al asegurado por los valores de mercado en el evento de siniestro de daño y/o de deterioro y/o costos/gastos adicionales -por cualquier causa- comprobables de carga de fruta y vegetales, resultante de: (...) 4. Directamente de actos maliciosos y/o sabotaje y/o terrorismo sufrido por la carga cometidos por cualquier persona o personas con el propósito de causar daño económico, tanto a cualquier fruta o vegetales asegurados, como el exportador y/o relaciones comerciales entre Chile y el país importador...".

Recordemos que la retención de la fruta en los recintos del puerto se originó por la paralización de los trabajadores portuarios, impidiendo la manipulación de los contenedores y la intervención del asegurado. De modo que, de no haber mediado la paralización, la fruta podría haberse embarcado oportunamente y comercializado en condiciones normales de mercado. Sin embargo, nada de ello ocurrió. La retención de la fruta, debido a la mencionada paralización, originó su detrimento que repercutió en el precio de venta. Asumiendo que los hechos descritos constituyeron actos deliberados calificados como "maliciosos y/o sabotaje" y que fueron la causa del daño a la fruta, concluimos que éste tuvo su causa en un riesgo expresamente descrito en la póliza y que, por ende, impone al asegurador la obligación de indemnizar al asegurado.

Para el caso que la paralización y consiguiente retención de las mercaderías no fueran calificados como un acto malicioso o de sabotaje en los términos de la póliza contratada, resultaría perfectamente aplicable la norma del artículo 535 del Código de Comercio que hace responsable al asegurador de los siniestros cubiertos por la póliza -el daño a las mercaderías- por un evento constitutivo de caso fortuito, comprendiendo los actos culposos o dolosos de terceros, como los serían los de los trabajadores portuarios. Al no existir exclusión expresa, sólo quedaría concluir la responsabilidad del asegurador. Según los artículos 531 y 1185 del Código de Comercio, al asegurador corresponde probar la exclusión del riesgo de la cobertura. Entonces, podemos coincidir que el siniestro 
"daño de la fruta" estaría subsumido en la póliza al ser una consecuencia de un riesgo que ella prevé y que de no ser de este modo, igualmente se alcanzaría la misma conclusión, porque, a falta de una estipulación expresa, el asegurador igualmente responde del caso fortuito y el hecho de tercero -la paralización y retención- bien podemos asimilarla al caso fortuito o a actos imputables a terceros según lo explicado.

De este modo, a falta de una estipulación sobre el límite de responsabilidad del asegurador o de una norma legal expresa, esta parte responde de la ocurrencia de todos los riesgos que por su naturaleza correspondan al ramo asegurado, inclusive cuando tal ocurrencia se deba a un caso fortuito en los términos del artículo 535 del Código de Comercio, a menos que el asegurador rinda prueba en sentido contrario.

\section{La prestación característica del asegurador y las consecuencias de su incumplimiento}

\section{Condiciones para el nacimiento de la obligación de indemnizar}

Los presupuestos para el nacimiento y activación de la obligación de indemnizar el siniestro conforme al contrato descansan en las siguientes condiciones: a) Existencia de un contrato de seguro válido; b) Cumplimiento del asegurado de sus obligaciones; c) Ausencia de una causal de extinción de la obligación del asegurador; d) Ocurrencia del siniestro durante la vigencia de la póliza, y e) Daños derivados de la ocurrencia de los riesgos previstos y cubiertos en la póliza.

Habiendo disipado cuáles son los elementos esenciales del seguro, corresponde ahora discernir cómo se configura la prestación del asegurador una vez ocurrido el riesgo. Asumiendo la transferencia de este último a cambio del pago efectivo de la prima, entendemos que la prestación del asegurador, cuyo nacimiento es eventual -al depender de la ocurrencia del riesgo de la cobertura-, consiste en dar una suma de dinero al asegurado, siempre y cuando aquél no tenga su causa en la propia voluntad del asegurado o en otra excluida por la ley o la partes. De este modo, la obligación del asegurador de indemnizar es condicional, pues en ella subyace la ocurrencia del riesgo previsto en el contrato (artículo 529 del Código de Comercio). Una vez que aquél acontece, se torna exigible la obligación de dar que el contrato pone de cargo del asegurador y, correlativamente, el asegurado está autorizado a exigir su ejecución ${ }^{34}$.

\footnotetext{
${ }^{34}$ El cumplimiento del contrato es un acto de realización del deber jurídico (la deuda) que pesa sobre el deudor; al mismo tiempo, representa la manera normal que éste tiene de liberarse de la obligación; y es, finalmente, la manera de satisfacer el derecho y el interés del acreedor. Dí́z-PıcAzo, (2008), p. 542.
} 
Para que la obligación de indemnizar nazca, deben concurrir varios supuestos. Primero, que exista un contrato de seguro vigente y que los riesgos hayan empezado a correr de cargo del asegurador; segundo, que se verifique un riesgo cubierto en la póliza (siniestro); tercero, que exista una relación de causalidad entre el siniestro y el daño. En este sentido, de acuerdo al art. 1177 del CCo., para obtener la indemnización de un siniestro, el asegurador deberá justificar: 1. El o los acontecimientos que lo constituyan. Respecto del origen del daño o gasto, el asegurado sólo deberá indicar los hechos que presumiblemente lo produjeron. Esta regla de causa presunta, requiere que el asegurado demuestre un mínimo grado de convicción acerca de la causa del daño o gasto cuya indemnización pretende. En tal sentido, el asegurado deberá probar los acontecimientos que constituyen el siniestro, y desde la perspectiva de la causalidad, deberá acreditar la causa, para lo cual el asegurado debe prevalerse de presunciones legales o judiciales. Debe considerarse a estos efectos, lo previsto en el art. 1184 ya relatado, en el evento que existan varias causas.

En cuanto a la oportunidad de ejecución de la prestación contractual, de acuerdo a los artículos 61 del D.F.L. No 251 y 27 del D.S. No 1.055, el asegurador debe cumplir a favor del asegurado su obligación de indemnizar el siniestro cubierto en la póliza "dentro de los seis días siguientes de notificada la resolución que acoge la procedencia del pago por parte del asegurador, salvo que la póliza disponga de un plazo distinto el cual, en todo caso, no podrá exceder de los seis días señalados anteriormente en el caso de las pólizas depositadas en la Superintendencia. En el mismo plazo, deberá ponerse a disposición del asegurado la suma no disputada, si la hubiere". Con ello se reconoce a las partes la libertad contractual para fijar un plazo diverso, pero con el límite máximo de los 6 días para las pólizas depositadas en la Superintendencia de Valores y Seguros.

En relación a la determinación del objeto de la obligación del asegurador de indemnizar, debemos considerar que, ocurrido el siniestro, sobre el asegurado pesa la carga de informar al asegurador la verificación del evento o suceso de peligro cubierto por la póliza ${ }^{35}$, dando lugar a un procedimiento complejo cuyo fin último es el ajuste de la pérdida al que se le denomina "Iiquidación del siniestro"36. Este

\footnotetext{
35 Se trata de una carga porque la necesidad de observar la conducta -informar la ocurrencia del siniestro y su observancia- cede en beneficio exclusivo del asegurado, ubicándole en la posición de adquirir el derecho a la indemnización, de modo que si no la observa queda privado del mismo aunque el siniestro esté cubierto en la póliza.

${ }^{36}$ El artículo 19 del D.S. № 1.055 dispone que "la liquidación tiene por fin establecer la ocurrencia de un siniestro, determinar si el siniestro está cubierto en la póliza contratada en una compañía de seguros determinada, y cuantificar el monto de la pérdida y de la indemnización a pagar (...)".
} 
proceso tiene un carácter técnico regulado normativamente, pero la decisión de respetarlo o no es facultativa para las partes ${ }^{37}$.

El contenido del informe de liquidación está determinado por el artículo 28 del citado D.S. No 1.055. El liquidador debe emitir una opinión técnica y fundada sobre la procedencia de la cobertura y la indemnización. Esta opinión deberá expresarse en términos claros y simples, de modo que permita una adecuada comprensión para el asegurado. La liquidación se realiza sobre la base de una serie de actividades que principian con la recepción de la denuncia del siniestro, el reclamo de indemnización y los antecedentes respectivos que envía el asegurador al liquidador. Esta actividad prosigue con la inspección del objeto dañado y el lugar del siniestro, evaluación de los daños y peritajes; y, culmina, con la entrega de un informe de liquidación. Si tal informe concluye con el rechazo del siniestro, deberá contener sus razones y justificación, en forma precisa y fundada. ¿Qué valor tiene este informe para la configuración de la obligación de indemnizar?

Con el objeto de comprender este punto, volveremos al caso.

Como se anticipó, el liquidador en su informe concluyó que el siniestro no estaba cubierto por la póliza, rechazándolo. Imaginemos que el liquidador, al emitir su informe, interpretó restrictivamente la póliza, entendiendo por acto malicioso aquél cometido con dolo, es decir, perpetrado por terceros con la intención positiva de inferir daño a la mercadería de propiedad del asegurado (artículo 44 del Código Civil). Entonces, el paro del Puerto de Valparaíso no revestiría este carácter, sino que los perjuicios reclamados por el asegurado se habrían originado por la demora en el proceso de embarque, y transporte de la carga a destino final, que se produjo a causa del mencionado paro en las labores portuarias, y tales perjuicios por demora no constituían un riesgo de la cobertura del contrato, sino uno expresamente excluido en la póliza.

Por su parte, como se indicó, el asegurador esgrimió la improcedencia de la pretensión de cumplimiento específico, alegando, entre otras cosas, el carácter vinculante del referido informe de liquidación. La primera que surge es si puede el asegurador oponerse al cumplimiento bajo el solo argumento del rechazo del siniestro por el liquidador. La respuesta es negativa pues tal informe carece de fuerza vinculante, sin interesar

\footnotetext{
${ }^{37}$ La liquidación de los siniestros y los liquidadores se encuentran regulada en nuestro país en los arts. 61 a 64 del Título III "De los auxiliares del comercio de seguros" del D.F.L. № 251, de 1931, que contiene la normativa del comercio de seguros en Chile y en el D.S. № 1.055, de fecha 29 de diciembre de 2012, que contiene el Reglamento de los auxiliares del Comercio de Seguros, entre ellos, los liquidadores.
} 
que el liquidador fuere nombrado de común acuerdo por las partes del contrato o por una de ellas.

En este punto, debemos tener presente que este informe podrá ser impugnado por las partes conforme a un procedimiento que la propia norma determina. En tal sentido, la opinión del liquidador en la conclusión de su informe no es vinculante ni para las partes, ni para el juez ordinario o arbitral que conozca de la controversia.

El valor probatorio que se asigna a este tipo de informes es el mismo que la ley asigna a la prueba pericial solicitada por una de las partes. Quiere decir que su mérito es el mismo que la ley asigna a los documentos privados emanados de un tercero ${ }^{38}$. Por consiguiente, este informe de liquidación constituye en la práctica un antecedente probatorio más que el juez ponderará junto con las restantes pruebas rendidas por las partes.

En síntesis, la configuración de la obligación de indemnizar presupone la realización de un "procedimiento de liquidación del siniestro" cuya finalidad es determinar la ocurrencia del mismo y si se trata de un riesgo cubierto en la póliza, la verificación de los daños causalmente vinculados con ese riesgo, su cobertura y su cuantificación. Este informe no es vinculante ni para las partes ni para el juez o árbitro que conozca de la controversia sobre el cumplimiento del contrato de seguro.

\section{Incumplimiento del asegurador y pretensión de cumplimiento específico}

Si el asegurador no cumple la obligación de indemnizar en el plazo previsto, el asegurado tiene derecho a exigir su cumplimiento específico de manera forzosa, esto es, el deber de indemnizar el daño provocado por el siniestro y la respectiva indemnización de daños causada por la mora, descartándose, por la propia naturaleza del contrato y para este caso en concreto, el remedio de la resolución. Ahora bien, no se trata de una doble indemnización, pues en la primera, tal como señalamos atrás, responde más bien al cumplimiento forzoso de la obligación contractual asumida por el asegurador, y la segunda a un efecto propio del cumplimiento tardío. En las siguientes líneas nos referiremos sólo al primero, dado que el segundo queda sometido a las reglas generales sobre el efecto del incumplimiento de las obligaciones dinerarias (art. 1559 CC).

En cuanto a las posibles defensas del asegurador, éste podría alegar que conforme al contrato, el riesgo que originó el daño no estaba dentro de la cobertura; que no existe una relación causal entre el riesgo y el daño producido; o que este último estaba excluido según las condiciones de la póliza. Asimismo,

38 Contreras (2014), p. 683. 
el asegurador podría apoyar su defensa en el incumplimiento de la parte demandante o asegurado, por ejemplo, la infracción de alguno de los deberes precontractuales de información que expresamente impone la ley, como ocurre con la preexistencia de un riesgo no declarado. En este camino, también podría oponer la excepción de contrato no cumplido cuando habiendo ocurrido el siniestro el asegurado no hubiera cumplido su obligación principal, cual es, la de pagar la prima íntegra y oportunamente. Finalmente, podría requerir la reducción de la indemnización demandada por el asegurado -cubierta por la póliza- cuando el asegurado hubiera omitido adoptar aquellas medidas que razonablemente podían esperarse de él según la buena fe y las circunstancias del caso en cumplimiento de su carga de mitigar establecida en los artículos 1180 y 524, ambos del Código de Comercio.

Más allá de ello, la extensión del cumplimiento dependerá fundamentalmente de la cobertura de la póliza, las circunstancias del siniestro y los daños que éste irrogue, determinando la cuantía de la indemnización y los rasgos particulares de esta última. Profundizaremos en estos dos puntos.

\section{A. La necesaria determinación de la cuantía de la indemnización conforme al contrato}

Desde la teoría general de las obligaciones, el asegurador contrae una obligación dineraria indeterminada, con la finalidad de reparar los daños provenientes de riesgos cubiertos por una póliza. El asegurador se obliga al pago de una suma de dinero, cuya determinación presupone la concurrencia de las condiciones para el nacimiento de la obligación indemnizatoria ya examinadas.

Ahora bien, emanado el informe del liquidador podrán configurarse, al menos, tres supuestos de incumplimiento que justificarían la demanda y la ulterior determinación de la cuantía resarcitoria: a) cuando el liquidador rechaza el siniestro de la cobertura y el asegurado no se contenta con tal conclusión; b) cuando el liquidador en su informe declare la cobertura del siniestro y el asegurador no lo acepte, negándose al pago de la indemnización, y c) en la misma hipótesis, pero el asegurado no se conforma con la determinación del valor de la indemnización. En estos tres casos, será el juez o árbitro quien deberá resolver si el asegurador incumplió el contrato, pronunciándose sobre la extensión de la indemnización y los daños que ella comprende, esto es, determinará la cuantía de la obligación dineraria con el fin de obligar al asegurador al cumplimiento contractual.

En síntesis, una particularidad del contrato de seguro implica asumir que su efecto característico -la indemnización de los daños cubiertos en la póliza- está representada por una obligación dineraria de cuantía indeterminada, cuya ejecución presupone, necesariamente, la fijación de aquélla. En esta dirección, el Código 
de Comercio establece una serie de reglas que permiten, con la colaboración de la voluntad de las partes, delimitar la extensión de tal obligación. Tal fijación es característica del seguro de daños, diferenciándose de los denominados seguros de indemnización subjetiva, como el seguro de vida, en el que la indemnización a que tiene derecho el asegurado coincide con el total de la suma pactada al momento de perfeccionamiento de la convención. La indemnización en esta última clase de contrato equivale en su justa medida con la suma asegurada ${ }^{39}$.

\section{B. Comprensión de la indemnización de daños en el contrato de seguro}

En los contratos de seguro de cosas rige el principio de la reparación examinado en la primera sección de este trabajo, recogido en el artículo 550 del Código de Comercio. Según tal principio, el seguro de daños es un contrato de mera indemnización y no puede jamás representar para el asegurado la oportunidad de una ganancia o enriquecimiento. Tal regla tiene su concreción en la idea que aunque el riesgo cubierto se extienda más allá del daño producido, el asegurado sólo tendrá derecho a la cobertura de este último.

El asegurador se obliga a indemnizar la pérdida hasta la concurrencia del valor de la cosa al tiempo del siniestro, resultando esencial la determinación del valor real de la cosa asegurada en tal momento, lo que dependerá de la naturaleza específica del objeto asegurado. La base de la tasación de la cosa es su valor comercial que surge de la oferta y demanda y que puede ser fijado de diversas formas. Sobre el asegurado pesa la carga de la prueba de tal valor. Habiéndose fijado el valor del daño, sea que exista acuerdo entre las partes o con la intervención judicial o arbitral, procederá su indemnización.

En el caso en comento, por mucho que el contrato cubriera el valor íntegro de la pérdida de la fruta, si a causa de riesgo de la cobertura ella sólo experimentó un detrimento, la indemnización no cubrirá el total del valor de la fruta, sino que se limitará al daño efectivo, esto es, el menor valor de su venta en el mercado.

Siguiendo el mismo razonamiento, si a pesar de la realización del riesgo -acto malicioso y retención de las mercaderías- la fruta no experimenta daño, el asegurado no tendría derecho a indemnización.

No obstante lo anterior, puede ocurrir que las partes hubieren convenido un monto asegurado que al momento del siniestro sea inferior al valor de la cosa objeto del contrato. Para este caso, el artículo 553 del Código de Comercio dispone que el asegurador indemnizará el daño a prorrata entre la cantidad asegurada y

39 Así se recoge en Veiga (2014), p. 1518. 
la que no lo esté. Con todo, las partes podrán pactar que no se aplique la regla proporcional antes prevista, en cuyo caso el asegurado no soportará parte alguna del daño si ocurriera un siniestro, a menos que éste exceda la suma asegurada.

En la hipótesis que recoge la norma, si la pérdida es total el asegurador, salvo pacto en contrario, no se obliga más allá del monto convenido resultando bastante sencilla la delimitación del alcance de la indemnización. Sin embargo, si la pérdida es parcial, se justifica la regla de proporcionalidad en la indemnización. En tal sentido, si al tiempo del siniestro el monto asegurado resulta ser inferior al valor de la cosa y ésta experimenta un deterioro, el asegurador quedará obligado a la indemnización proporcional según la diferencia entre ambos valores (el asegurado y el de la cosa), lo que envuelve una reducción de la indemnización en proporción a tal diferencia. En otras palabras, si la cosa sufre un daño avaluado en 200, y su valor al tiempo del siniestro, de no haber mediado aquel daño, hubiese sido de 600, y el monto asegurado se fijó en 400, el asegurado tendría derecho a la indemnización por deterioro con reducción proporcional según la diferencia entre el valor que habría tenido la cosa al tiempo del siniestro (600) y el monto asegurado (400), esto es, un 33,3\% menos, respecto del menor valor real de la cosa.

También podría suceder que, habiendo las partes fijado un límite al monto asegurado, el valor del objeto asegurado al tiempo del siniestro fuese inferior a tal límite. Si aplicamos el principio que contiene el citado artículo 550, la indemnización a que tendrá derecho el asegurado se limitará a tal valor, aunque la suma asegurada hubiese sido superior. Sólo así se observa el principio de indemnización que rige en esta materia.

\section{Particularidades del régimen legal del seguro marítimo en materia indemnizatoria}

En lo que concierne a la comprensión de la indemnización a que puede quedar obligado el asegurador, en materia de seguro marítimo la regla general es que ella comprenderá "las pérdidas o daños originados por riesgos marítimos u otros eventos cubiertos por la póliza" (artículo 1180 Código de Comercio) y se añade que, salvo exclusión expresa por las partes, también queda obligado a indemnizar: 1. Por la contribución de los objetos asegurados en avería común, salvo si ésta proviene de un riesgo excluido; y 2 . Por los gastos incurridos con la finalidad de evitar que el objeto asegurado sufra un daño o para disminuir sus efectos, entendiendo que el daño evitado estaba cubierto ${ }^{40}$.

\footnotetext{
${ }^{40}$ La misma regla se encuentra en el régimen general del seguro, particularmente, en el artículo 524 del Código de Comercio.
} 
En lo que concierne a los daños del numeral dos, es sabido que la disposición ha servido a la doctrina para configurar una manifestación positiva de la carga de minimizar el daño, sobre la cual nos pronunciamos en la primera parte de este trabajo con ocasión de principio de la reparación. Como se anticipó, el fundamento de la imposición de esta carga al asegurado tiene su asiento en el principio de la buena fe objetiva contemplada en el artículo 1546 del Código Civil y la rebaja en la indemnización se justifica en la regla de la causalidad, puesto que tal daño -el razonablemente evitable para el asegurado- no es consecuencia de la realización del siniestro sino de la omisión del asegurado.

Volvamos a nuestro caso a objeto de ilustrar lo expresado.

Pensemos por un instante que ocurridos los hechos descritos, el asegurado embarca la fruta -con el detrimento aludido-, empero habiendo pluralidad de mercados para ella, se inclina por revenderla a un cliente que le ofrecía un precio ostensiblemente inferior al que podría haber obtenido al obrar como lo habría hecho un operador razonable en su lugar y circunstancias. La interrogante que surge es ipodemos entender que el asegurado adoptó las medidas pertinentes, habida cuenta las circunstancias del caso, para minimizar el daño? La respuesta es negativa y el efecto de esta omisión en la conducta del asegurado consiste en la rebaja de la indemnización a que resulte obligado el asegurador conforme al contrato. De este modo, si el precio de reventa de fruta sana era de US\$18 por unidad y se revendió a US\$12, no obstante que el promedio de re venta de la fruta dañada era de US\$14, resulta evidente que el asegurado infringió su deber de minimizar dado que debió haber revendido al último precio y no al primero. Como no lo hizo, se deberá aplicar la sanción por dicha infracción y procederá la reducción de la indemnización de US\$ 6 a US\$ 4 por unidad (diferencia de precio fruta sana y de precio de fruta dañada). Observamos que el daño efectivo y, en principio, cubierto por la póliza, ascendía a US\$ 6, empero por la regla de la causalidad opera su rebaja a US\$ 4 por unidad, dado que la diferencia de 2 US\$ es imputable al asegurado y no a la realización del siniestro, debiendo excluirse de la indemnización.

También, hemos de considerar, dentro del régimen especial de este seguro, la disposición del artículo 1191 del Código de Comercio toma distancia de la regla contenida en el inciso primero del artículo 553 del citado Código, en tanto, salvo disposición en contrario, el asegurador responde por todos los siniestros que sufra la cosa asegurada durante el período de cobertura, aunque su monto exceda la suma total asegurada, salvo en la hipótesis que a un daño parcial que no hubiera sido objeto de reparación, le siga su pérdida total, caso en el cual, el asegurado sólo tendrá derecho a la indemnización de esta última pérdida que comprenderá el total del valor de la cosa asegurada. 
De la interpretación del precepto en referencia aparece que en seguro marítimo se adopta la regla inversa, toda vez que la indemnización cubrirá todo daño aunque exceda el monto asegurado, salvo la presencia de una estipulación en contrario. No debemos olvidar que el régimen de esta clase de seguro es, por regla general, disponible. De esta forma, al caso planteado se aplicaría el artículo 1191 y no el artículo 553 del Código de Comercio.

En efecto, las frutas experimentaron un deterioro o detrimento que provocó la disminución de su valor. Imaginemos que las partes convinieron un monto asegurado en un USD 1.000.000 y que los daños experimentados por las mercancías - debido a su pérdida total al resultar inservibles para el propósito del asegurado- lo exceden. La solución consiste en que el asegurador, pese al monto fijado, igualmente quedará obligado a la indemnización del total del importe del daño, esto es, USD 1.200.000. La regla aplicará siempre que las partes no hubieran incorporado un límite máximo a la indemnización, pues en este último caso no podría exceder tal límite. El problema que se suscita en este último supuesto está relacionado con casos de deterioro o pérdida parcial de la mercadería. La norma del seguro marítimo no da una solución y, como la norma general de seguros suple los vacíos del régimen especial, a nuestro juicio, cabría perfectamente aplicar la norma de la proporcionalidad de la indemnización que se traduciría en lo siguiente. Si consideramos que el monto máximo asegurado es la suma de USD 1.000.000 y el valor de la fruta era de USD 1.200.000, si aplicamos la citada regla, habida cuenta que la fruta experimentó un detrimento, interesa calcular la cuantía de la indemnización que quedaría sujeta a una reducción proporcional según fuere la diferencia entre el límite máximo y el valor del objeto del contrato. Siguiendo la ilustración, imaginemos que el menor valor de la fruta por el detrimento es de USD 200.000 y la diferencia entre monto máximo y valor del objeto equivale a un $25 \%$ menos, por lo que la reducción que se aplica a la indemnización ascendería a la suma de USD 50.000, quedando firme una indemnización de USD 150.000. En el primer caso, aplicando el artículo 1191 la indemnización se calcula atendiendo la diferencia directa; en cambio, si hay pacto y se fija un monto máximo, se considera lo que podríamos denominar la diferencia relativa que incluye la rebaja proporcional.

Finalmente, según el artículo 1182 del Código de Comercio, el asegurador no responde de las pérdidas causadas por demora, aun cuando ella tuviere su origen en un riesgo cubierto por la póliza, precepto que se justifica en la característica propia de este riesgo, que no se manifiesta en un acontecimiento súbito o instantáneo, sino en diversos acontecimientos, incluyendo la simple desidia 
del embarcador. Por razones similares, salvo pacto en contrario, el asegurador no es responsable por los fenómenos ordinarios de filtración, rotura o desgaste, por vicio propio de la naturaleza de la cosa asegurada y otros normales de transporte (artículo 1183 del Código de Comercio).

\section{Procedencia de la pretensión de cumplimiento específico. Legitimación activa y condiciones}

\section{A. Legitimación activa del asegurado para reclamar el cumplimiento del contrato de seguro}

La primera cuestión que debe dilucidarse es quién tiene legitimación activa. Para aclarar este punto en el contrato de seguro debemos considerar que el artículo 513 letra n), al reglar sobre el interés asegurable prescribe que éste es: "(...) aquél que tiene el asegurado en la no realización del riesgo, sin perjuicio de lo dispuesto en el artículo 589 en relación a los seguros de personas". Entonces, el asegurado debe ser titular de un interés asegurable, actual o futuro, respecto del objeto del contrato.

Es preciso que ese interés exista al momento de ocurrir el siniestro, si el interés no llegare a existir o cesare durante la vigencia del seguro, éste terminará y el asegurado tendrá derecho a la restitución de aquella parte de la prima correspondiente al tiempo que falte para el término pactado inicialmente en el contrato (artículo 520 del Código de Comercio). Este interés tiene un carácter claramente subjetivo y pertenece al asegurado.

En la legislación chilena, la existencia del interés asegurable no constituye un requisito de validez del contrato -con excepción de los seguros de personas-, sino una condición de su eficacia, en términos que si no llega a existir o cesa durante su vigencia, se producirá la terminación del contrato, dejando de producir los efectos que le son propios. En el caso del seguro marítimo, el artículo 1164 del Código de Comercio dispone que puede celebrar este contrato toda persona que tenga interés en la conservación de la cosa asegurada mientras corra los riesgos de esa clase, sea que aquél afecte directamente a su patrimonio o a determinadas obligaciones suyas con relación a la cosa asegurada. Seguidamente, el artículo 1165 expresa que el asegurado "sólo debe justificar su interés asegurable en la época en que ocurra la pérdida o daño de la cosa asegurada"; disposición que coincide con la del artículo 520 ya comentado.

Si vamos al caso: ¿Concurre el interés del que se habla en el asegurado que le confiera legitimación activa para demandar el cumplimiento del contrato? La respuesta es afirmativa. El asegurado, en calidad de propietario de la carga, es titular del interés de conservación respecto de la misma y tal interés persiste al momento de la ocurrencia del siniestro. Resulta claro que el asegurado tenía interés asegurable, tanto cuando celebró el contrato 
de seguro, como en el momento en que ocurrió el siniestro y los daños en las mercaderías aseguradas, toda vez que se trataba de su propietario y su intención inequívoca era comerciar la fruta al mejor precio.

\section{B. Condiciones de procedencia de la pretensión de cumplimiento específico}

El artículo 27 del D.S. № 1.055 de 2012, que Aprueba nuevo Reglamento de los Auxiliares de Comercio de Seguros y Procedimiento de liquidación de siniestros, prevé que si habiéndose liquidado el siniestro, persisten diferencias entre el asegurador y asegurado respecto de la procedencia de la indemnización, la compañía de seguros deberá notificar al asegurado su resolución final respecto del siniestro, debiendo siempre informar al asegurado su derecho a recurrir al procedimiento establecido por la póliza o al que corresponde conforme la ley, para reclamar el pago de la pretendida indemnización.

Entonces, si se considera que la indemnización del siniestro constituye un derecho esencial del asegurado; que el artículo 1489 del CC reconoce al acreedor afectado por el cumplimiento el derecho a exigir la ejecución de la obligación correlativa; y lo prescrito por el citado artículo 27, no cabe duda acerca de la procedencia de la acción de cumplimiento forzado en esta clase de contrato, quedando pendiente develar sus condiciones de procedencia.

Tratándose de las obligaciones dinerarias, como lo es la de indemnizar por parte del asegurador, tales condiciones son: a) la existencia de la obligación de indemnizar ${ }^{41}$; b) el incumplimiento del asegurador, y c) que la obligación sea líquida y determinada.

Ante la ocurrencia del siniestro, concurriendo las condiciones para el nacimiento de la obligación de indemnizar, lo esperable es que el asegurador cumpla según lo convenido, ejecutando la prestación debida, esto es, dando al asegurado la suma de dinero que corresponda conforme el contrato. Sin embargo, si el asegurador no cumple o cumple imperfectamente, el contrato reconoce al asegurado el remedio de la pretensión de cumplimiento específico a objeto de obtener la ejecución de la prestación debida. Como el nacimiento de la obligación está sujeto a la concurrencia de ciertas condiciones vinculadas con el riesgo previsto y la cuantía de la obligación es indeterminada, será el juez o árbitro quien necesariamente se pronunciará sobre si hubo o no incumplimiento, principalmente porque la primera discusión entre las partes referirá a si surgió o no la obligación para el asegurador y, luego, de estimarse que ella nació, el debate se centrará en el quantum de lo adeudado.

${ }^{41}$ Que presupone la concurrencia de las condiciones arriba tratadas, esto es, ocurrencia de un riesgo previsto en el contrato y el daño y su relación de causalidad con el riesgo. 
En el caso, el asegurador alegó la improcedencia del ejercicio de la pretensión de cumplimiento específico, principalmente, porque al haber concurrido el asegurado a la designación de los liquidadores del seguro, el informe emitido le sería vinculante, de modo que el rechazo contenido en tal informe, justificaría el no nacimiento de la obligación. Tal defensa es errada, principalmente, por dos razones: Primero, porque el informe del liquidador, aun designado por ambas partes, no vincula al asegurado que no se conforme con sus conclusiones, siendo la propia ley la que reconoce el derecho a exigir al Tribunal-ordinario o arbitral- la indemnización del siniestro objeto de contrato, esto es, la ejecución contractual. Seguidamente, porque al ser el seguro un contrato bilateral, ante el incumplimiento de una de las partes -en este caso el asegurador-, el otro contratante-Asegurado- puede optar, a su arbitrio, entre la resolución o el cumplimiento del contrato, en ambos casos, con indemnización de daños. De este modo, el cumplimiento forzado es un derecho que el propio contrato y la ley reconocen a la demandante.

\section{Determinación del contenido de la prestación: el daño asegurado}

Habiendo develado las reglas que gobiernan la extensión de la indemnización, corresponde detenernos en los daños que ella comprende o puede comprender según lo estipulado por las partes.

En la determinación de la indemnización se debe tener en cuenta el interés asegurable y la suma asegurada prevista en la póliza ${ }^{42}$, lo que implica que el resarcimiento probablemente no será completo o satisfactorio del todo para el asegurado, al existir una correlación normalmente distante entre aquéllas ${ }^{43}$. Esto ocurre porque los seguros de daños, a diferencia de los de personas, están sometidos a una limitación doble: una legal que pretende el resarcimiento, y otra convencional recogida en la póliza.

La realización del riesgo que produce el daño configura el siniestro. Se trata de un hecho material dañoso que se concreta; de la verificación de una probabilidad que era incierta y que ahora es objeto del resarcimiento o indemnización. Pero ¿cuándo se produce el siniestro y cómo se computa el daño?, ¿es el hecho dañoso por sí mismo constitutivo del siniestro, o por el contrario, la causa del mismo o la fuente que obliga a la indemnización? ${ }^{44}$ Consideramos que sólo desde el momento en que se produce el hecho dañoso se configura el

42 Ballester (1997), p. 90.

43 Veiga (2014), p. 1504.

44 Sobre este debate, VeIGA (2014), p. 1512. 
siniestro y, con ello, el motor de la obligación indemnizatoria, de manera que al producirse el hecho dañoso nace una deuda para el asegurador.

En principio, la indemnización sólo comprende el daño emergente causado directa e inmediatamente por la ocurrencia del siniestro, excluyéndose el lucro cesante o pérdida de ganancias, partida que sólo quedará comprendida en caso que las partes así lo acuerden expresamente según el artículo 551 del Código de Comercio, que dispone: "Para que el lucro cesante del asegurado esté cubierto, deberá ser pactado expresamente" 45 .

Para descifrar el contenido de la indemnización en el seguro conviene acudir a una tipología de daños propia de la responsabilidad civil en el common law y en el derecho europeo de los contratos, que estimamos de utilidad para los fines de la presente sección ${ }^{46}$. El recurso a esta tipología nos permitirá ilustrar, a partir de lo expresado y el caso planteado, las reglas sobre los daños que puede comprender la cobertura del seguro. La finalidad de ello es presentar una mirada más amplia de la noción de esta materia, superando la tradicional distinción del daño patrimonial entre daño emergente y lucro cesante. Lo anterior, sin perjuicio de las inclusiones o exclusiones que pudieran convenir las partes.

En general, podemos distinguir tres clases de daños: aquel que incide en el objeto mismo de la prestación (daño al valor del objeto asegurado) (a); daños incidentales -que sin ser directos se origina con ocasión de la ocurrencia del riesgo previsto (b) y los denominados daños consecuenciales (c).

\section{Los daños al objeto asegurado ${ }^{47}$}

Alude a una disminución del valor de la cosa u objeto asegurado como consecuencia de su deterioro, la que normalmente constituirá un riesgo previsto por las partes. Hecha la aclaración podemos decir que esta especie de daño consiste en un detrimento intrínseco del objeto asegurado, este daño puede

\footnotetext{
45 Sobre el particular, cabe consignar que hasta antes de la reforma de la ley $N^{\circ} 20.667$, el antiguo artículo 522 excluía de la cobertura la pérdida de ganancias o de beneficios esperados, esto es, el lucro cesante y, por ende, su indemnización.

${ }^{46}$ En el Restatement Law Second Contracts $2^{\text {nd }}$ la indemnización de daños comprende los "loss in value", "incidental loss" y "consequential loss". La Sección 347 dispone que la indemnización de daños comprende: "(a) the loss in value to him of the oyher party's performance caused by its failure or deficiency, plus (b) any other loss, including incidental or consequential loss, caused by the breach (...)". Para la CISG véase: VIDAL (2006), pp. 118-132.

47 En la doctrina Farnsworth, refiriéndose a la "loss in value" asevera que el primer daño que puede causar el incumplimiento es la privación al acreedor afectado, al menos en alguna medida, del cumplimiento que debía recibir conforme el contrato y corresponde a la diferencia entre el valor del cumplimiento que debió recibir la parte afectada y el valor que para ella tiene el cumplimiento recibido. FARNSWORTH (2004), p. 79.
} 
consistir en anomalías físicas o funcionales ${ }^{48}$ que afectan la habilidad de la cosa para el fin propuesto ${ }^{49}$. Tal anomalía puede originar una pérdida total o una disminución de su valor que incidirá en su precio de venta en el caso de especies comerciables. La diferencia entre ambas radica en su utilidad, toda vez que si la cosa sigue siendo útil o idónea para conseguir el fin propuesto por el asegurado, el defecto sólo provocará la disminución de su valor, reflejándose en un menor precio de venta para las mercaderías.

Si tuviésemos que encajar esta especie de daño con aquél cuya indemnización pretende el asegurado en el caso planteado, podemos decir lo siguiente:

Éste calzaría con aquella partida de daño emergente reclamada, consistente en la disminución del valor de las mercaderías provocada por la pérdida de atributos de la fruta que le hizo inhábil para su finalidad original, esto es, su exportación como "fruta fresca", y que forzó a la asegurada -observando su carga de mitigar los daños- a venderlas en un mercado diverso al previsto a un precio inferior de aquel que hubiera obtenido de no haber ocurrido el siniestro. El daño reclamado por el asegurado tuvo su causa directa e inmediata en la paralización portuaria y retención de los contenedores; de este modo, la disminución o el menor precio de las mercaderías aseguradas tuvo su causa en estos hechos y no en fluctuaciones del mercado como podría alegar el asegurador.

\section{Daños incidentales}

En materia de incumplimiento contractual esta especie de daños corresponde a aquellos costos en que incurre el acreedor agraviado con ocasión de la infracción de la prestación debida y otros posteriores a ella. Treitel, junto con reconocer la dificultad de enmarcar fácilmente este daño en las categorías tradicionales, ofrece una definición de daños incidentales aseverando que el acreedor puede incurrir en gastos con posterioridad al incumplimiento y con ocasión del mismo, como podría ocurrir con los gastos de una operación de reemplazo, o del envío de regreso de las mercaderías defectuosas, o de la mano de obra de su personal ${ }^{50}$.

\footnotetext{
48 De Verda y Beamonte (2009), pp. 313-317.

${ }^{49}$ En Chile, distinguiendo las anomalías materiales, en las que incluye a las funcionales, de las jurídicas (derechos de terceros), De La MaZa (2015), pp. 79-100.

50 Peel \& Treitel (2011), p. 1099. Así se recoge de la Sección 2-715 del Uniform Commercial Code norteamericano al autorizar al comprador para recobrar de vendedor los daños incidentales (incidental loss) que cualquier incumplimiento le hubiere irrogado, precisando que esta clase de daños incluyen los gastos razonables incurridos en la inspección, recepción, transporte, cuidado, custodia de las
} 
Estos daños pueden tener su causa en la determinación del incumplimiento, la fijación de sus consecuencias, la eventual conservación del objeto de la prestación, o en la mitigación de las pérdidas ${ }^{51}$. En materia de seguros, el artículo 524 del Código de Comercio reconoce expresamente esta especie de daño, norma que junto con imponer al asegurado la obligación de adoptar todas las providencias necesarias para salvar la cosa asegurada o para conservar sus restos ante la ocurrencia del siniestro $\left(\mathrm{N}^{\circ} 6\right)$, le asigna al asegurador la obligación de reembolsar los gastos en que razonablemente haya incurrido el asegurado para cumplir las obligaciones expresadas en el numeral $6^{\circ}$, fijando como límite del reembolso la suma asegurada. Por su parte, el artículo 1180 del Código de Comercio, reiterando parcialmente la regla, incluye en la indemnización los gastos incurridos con la finalidad de evitar que el objeto asegurado sufra un daño o para disminuir sus efectos, entendiendo que el daño evitado también estaba cubierto. No obstante las diferencias que podrían detectarse entre ambas disposiciones, interesa precisar que si ella se conecta con el citado artículo 524, en tanto norma supletoria, el seguro marítimo también impondría al asegurado el empleo de la debida diligencia y celo en la prevención del sinestro y en la evitación de daños y conservación del objeto dañado.

De la conjunción de ambas disposiciones es posible construir una regla similar a la que rige en el derecho uniforme de la compraventa internacional, contenida en el artículo 77 de la CISG en términos que el acreedor (asegurado) debe adoptar todas las medidas que sean razonables, atendidas las circunstancias, para mitigar las pérdidas que se sigan del incumplimiento (siniestro), añadiendo -y aquí encontramos un complemento a las normas citadas- que de no hacerlo la indemnización queda sujeta a reducción en la medida del daño que era razonablemente evitable ${ }^{52}$. Con todo, destaca el hecho que la regla del Código de Comercio explicita la obligación de indemnizar los daños incidentales -costos de las medidas de mitigación ${ }^{53}-$, lo que no hace el

mercaderías correctamente rechazadas; cualquier cargo, gasto o comisión comercialmente razonable en que incurra el comprador en la celebración de operación de cobertura o reemplazo; y cualquier otro gasto incidental del retraso u otro incumplimiento del vendedor. $Y$ en la doctrina que comenta la disposición se afirma que esta clase de daño comprende los costos adicionales en que incurre el acreedor después del incumplimiento en un intento razonable de evitar, o aminorar, las pérdidas, aunque el intento sea infructuoso. FARNSWORTH (2004).

${ }^{51}$ En Chile, refiriéndose a esta clase de daños en la mitigación de las pérdidas: SAN MARTín (2012), pp. 403-407; VIDAL (2008), pp. 446-447.

52 Sobre esta materia, véase: Bercovitz (2013), pp. 628 y siguientes.

${ }^{53}$ El artículo 9.905 (reducción de las pérdidas) de los PECL dispone que: "(1) La parte incumplidora no es responsable de las pérdidas que hubiese sufrido la parte perjudicada en la medida en que ésta última hubiera podido reducirla adoptando para ello las medidas razonables" y agrega que: "(2) La 
mencionado artículo 77, pese a que existe acuerdo acerca de reconocer este derecho al acreedor ${ }^{54}$.

Los daños incidentales no son una consecuencia directa e inmediata de la realización del siniestro (causalidad), sino que provienen de la propia actividad del asegurado, que debe desplegar por imperativos de la buena fe. Cabe consignar que nuestra Corte Suprema, a propósito de una demanda indemnizatoria por incumplimiento, rechazó la inclusión en la indemnización de un daño incidental bajo el argumento que no se trataría de un daño que satisfaga la exigencia de la causalidad al no tener su origen en la acción u omisión del deudor, sino del propio acreedor ${ }^{55}$. Se trata de una especie de daño que no ha sido reconocida por nuestra doctrina y jurisprudencia, no obstante que -sin calificarla como tal- tiene reconocimiento legal en materia de seguro general y marítimo.

De hecho, nadie podría poner en duda que el Código de Comercio impone al asegurado la carga de adoptar medidas o providencias necesarias para la mitigación del daño y que al mismo tiempo le reconoce el derecho a la indemnización de los costos en que incurra en tal adopción, a condición que sean razonables y su importe no exceda el monto asegurado (inciso segundo del artículo 524 del Código de Comercio).

Si volvemos al caso, podemos afirmar lo siguiente. Entendemos que el asegurado cumplió con esta carga al proceder a la pronta venta de la fruta dañada en un mercado alternativo, minimizado los daños subsecuentes del siniestro. De este modo, el asegurado tiene derecho a acceder a la indemnización total del daño (disminución de valor) y no sólo eso, sino que si incurrió en gastos -razonables atendidas las circunstancias- tendría derecho a incluirlos en la demanda y obtener su reembolso según lo disponen los artículos 524 y 1180, ambos del Código de Comercio. Si este es el caso, imaginemos que el asegurado en su demanda incluye los "costos adicionales" por concepto de retiro de los contenedores, los cuales permanecían en el Puerto y que debieron ser devueltos a la planta de origen para la revisión de la carga y, posteriormente, redestinados,

\footnotetext{
parte perjudicada tiene derecho a recuperar cualesquiera gastos en que razonablemente haya incurrido al intentar reducir las pérdidas".

${ }^{54}$ Vidal asevera: "este precepto (el artículo 77 CISG), a diferencia de los PCCl y los PECL, como también el Restatement of the Law y el NBW, no dispone sobre la indemnización de los costos incurridos en la adopción de las medidas mitigadoras. Sin embargo, esta omisión no obsta su indemnización, puesto que a ella se llega por aplicación de la regla general del artículo 74 CV. La indemnización comprenderá estos costos en la medida que sean razonables atendidas las circunstancias". VIDAL (2008), p. 446. También, Stoll (1998), p. 586.

55 Para un comentario de esta sentencia respecto de este punto, véase: Morales et al. (2014), pp. 1167 y ss.
} 
incurriéndose en costos de flete, sobre estadía, uso de underlung, costos de pre-frío y diferencia de fletes, entre otros; como asimismo, aquellos costos incurridos y reclamados por su consignatario en un país distinto al original a causa de la redestinación y comercialización de la fruta. No cabe duda que se trataría de costos en que hubo de incurrir el asegurado a objeto de evitar el agravamiento de las consecuencias del siniestro. Si el juez valora tales gastos como razonables y estima que el asegurado incurrió en ellos en observancia de la exigencia contenida en las disposiciones citadas, sería procedente su indemnización como "daños incidentales" en los términos explicados. Más aún, el asegurado cumplió su deber de minimizar el daño, evitando que las frutas perecieran lo que habría provocado su pérdida total, lo que habría ocasionado no sólo la rebaja de la indemnización, sino su vaciamiento ${ }^{56}$.

\section{Pérdidas consecuenciales}

Los daños consecuenciales corresponden a aquellas pérdidas que el acreedor experimenta en otros bienes diversos al objeto de la prestación, en este caso, del contrato de seguro. En la terminología de Pothier eran conocidos como daños extrínsecos, en oposición a los intrínsecos que refieren al valor del objeto de la prestación (daño al objeto de la prestación). Esta especie de daños puede entenderse en un sentido amplio y otro restringido; en el primero, se comprenden las pérdidas que afectan las expectativas del acreedor respecto del cumplimiento mismo, situadas más allá del objeto de la prestación. Serían de esta especie el lucro cesante, las indemnizaciones a que pueda quedar obligado el acreedor frente a terceros por el incumplimiento, y, también, las pérdidas resultantes de la lesión de intereses del acreedor distintos al que recae en el objeto de la prestación misma, como el interés a la integridad patrimonial y personal del acreedor ${ }^{57}$. El segundo -el restringido- se refiere exclusivamente a esta última clase de daño, esto es, la lesión a la integridad patrimonial y personal del acreedor. A partir de lo expresado se diferencia claramente el daño al objeto de la prestación de los denominados consecuenciales ${ }^{58}$.

\footnotetext{
56 VIDAL (2005), pp. 76-77.

57 Pantaleón (1998), p. 592; y Morales, (2011), pp. 263 y ss.

58 Morales Moreno, refiriéndose a esta clase de daños, expresa que: "podemos, en primer lugar, contraponer entre el daño que directamente implica la insatisfacciónn de interés expectante, que el cumplimiento del contrato está llamado a cumplir, y otros daños más o menos remotos o consecuentes, que se producen por causa del incumplimiento. Si, por ejemplo, el vendedor entrega un animal enfermo, incumpliendo su obligación, hay un daño directo que experimenta el acreedor, al recibir un animal enfermo en lugar de un animal sano. Este daño es manifestación de la insatisfacción de su interés. Pero
} 
En nuestro caso, si el asegurado hubiese pretendido incluir en la indemnización del lucro cesante por las utilidades que dejó de percibir a causa de la ocurrencia del siniestro, junto con la indemnización a que fue obligado para con su comprador original de "fruta fresca"; y el daño moral por la lesión a su honor y nombre comercial, estaría persiguiendo la indemnización de daños consecuenciales. El elemento que comparten estas partidas de daños descritas es que refieren a pérdidas que experimenta el asegurado que sobrepasan el objeto mismo del seguro, de manera que son daños que se sitúan más allá del valor del objeto asegurado. No debemos olvidar que en la presentación del caso se considera una cláusula de exclusión de la póliza que tiene el siguiente tenor: "3. Pérdida consecuencial. Excluyen cualquier pérdida consecuencial, incluyendo, pero no limitándose a la interrupción de los negocios, retraso, deterioro y/o pérdida de mercado".

Surge la duda si esta exclusión considera al lucro cesante. La respuesta no la encontramos en la póliza, sino que -como hemos explicado más atrás-, se encuentra en la propia ley que excluye la indemnización el lucro cesante, salvo pacto expreso en contrario que no se incorporó a este contrato. Siendo así, el lucro cesante y los restantes daños consecuenciales según las explicaciones que anteceden, estarían excluidos del objeto de la indemnización, sin que sea relevante el que el asegurado efectivamente los haya experimentado. El riesgo de su ocurrencia pertenece a este último, debiendo soportarlas en su patrimonio.

Conviene detenernos en dos puntos que resultan de especial interés no sólo para la resolución del caso, sino para la comprensión del objeto de estudio; el primero concierne al alcance de la cláusula de exclusión transcrita que alude a las pérdidas consecuenciales que pueda sufrir el asegurado como deterioro y/o pérdida en el mercado. Sobre el particular cabe resaltar que el asegurado no alega, ni reclama la indemnización de la disminución en el precio de venta por variaciones en el comportamiento del mercado -como lo sería una crisis económica- producida durante el período de retención de las mercaderías hasta su embarque. La exclusión de la póliza y su aplicación presupone que pese a que las mercaderías hubieren conservando todos sus atributos y cualidades, su

si el animal enfermo, además, contagia a otros animales del acreedor y todos ellos mueren, se está produciendo un daño subsecuente, derivado del incumplimiento". Díez-Picazo et al. (2002), pp. 374375. Claramente, el jurista distingue lo que nosotros hemos denominado daño al valor del objeto de la prestación -que denomina directo- de los llamados daños subsecuentes, a los que nosotros hemos denominado consecuenciales, adhiriendo la terminología empleada por la póliza. 
precio cae o su mercado desaparece por causas externas e incontrolables para el asegurador. En la hipótesis que interesa, la disminución de valor de la fruta tuvo su origen en el detrimento que experimentó por la paralización y retención, al no poder venderse como "fruta fresca", sino en una condición inferior. Así planteadas las cosas, la disminución de precio de la fruta no obedeció a una causa externa del mercado, sino que fue consecuencia directa e inmediata de la paralización y retención sufrida. Resulta interesante esta reflexión porque evidencia que una mercadería puede ver disminuido su valor por razones intrínsecas, como es el caso de la pérdida de atributos de la fruta, o por razones extrínsecas como lo sería una variación o alteración en el mercado de la fruta indemne debido a la demora en el embarque y arribo a destino. El primer riesgo fue cubierto por la póliza, no así el segundo.

El segundo punto nos lleva a discernir si la reclamación de la indemnización del menor precio de venta de la fruta constituye o no un daño consecuencial. La pregunta se justifica porque cuando nos planteamos el problema del daño en la cosa asegurada aparecen dos valores relevantes: el del objeto asegurado al momento del siniestro y el del precio de venta en el mercado. A primera vista podríamos pensar que el primero difiere del segundo porque éste tendría incorporada la utilidad o ganancia que esperaba obtener el asegurado, sin embargo, para resolver el asunto resulta esencial atender a la naturaleza de la cosa asegurada. Si esta última es una especie o cuerpo cierto que el asegurado embarcará y transportará a puerto de destino para venderla allí a un precio que había convenido con su comprador y tal especie se deteriora o destruye, es pertinente para resolver el problema del daño comprendido en el seguro la distinción propuesta, siendo relevante considerar el valor o el precio de venta, dado que este último sí incorpora un lucro o ganancia. En cambio, si son mercaderías fungibles con precio de mercado, tal distinción se diluye porque para un comerciante el valor de la fruta se identifica con el precio de mercado, no hay manera de escindirlos, ni menos entender que el precio de la fruta incluiría un lucro. La fruta de propiedad del asegurado tiene un valor de mercado y ese valor es el que integra su patrimonio, sin que sea permitido hablar de lucro.

Otra situación diversa es que el asegurado considere un precio exorbitante o extraordinario porque había hecho un muy buen negocio en el extranjero. En este último supuesto la solución variaría y estaríamos obligados a fijar la diferencia entre el valor de la fruta (precio ordinario de mercado) y el precio extraordinario de venta, excluyéndola por constituir una utilidad o lucro cuya pérdida (lucro cesante) está excluida expresamente por la póliza al ser una manifestación de daño consecuencial ${ }^{59}$.

${ }^{59}$ En este sentido: Morales (2010), p. 50. 
Para el caso en comento, si tuviésemos que fijar el valor de la fruta dañada tendríamos que acudir al mercado de destino, toda vez que se trata de mercaderías de exportación. Para un exportador no interesa otro valor que el de venta, puesto que aquél es el que integra su patrimonio. De esta manera, si el precio de mercado es de USD 10, ese es el valor de la fruta y si se vende en USD 6, la disminución de valor se confunde con la de su precio. Las cosas cambiarían si el exportador hubiese celebrado un contrato especialmente lucrativo con un importador acordando un precio de USD 20, la diferencia entre el precio concreto de venta (USD 6) y el proyectado (USD 20) comprendería no sólo daño emergente (USD 6), sino también la pérdida del lucro (USD 10). Si la asegurada pretendiera la indemnización de los USD 14 estaría quebrantando el contrato de seguro que excluye expresamente las pérdidas consecuenciales y la norma legal que deja fuera al lucro cesante. En consecuencia, tratándose de mercaderías aseguradas con precio de mercado, no hay forma de diferenciar este precio de su valor, salvo que el primero exceda al de mercado.

Entonces, en cuanto a los daños cubiertos en la póliza, cuya indemnización debe el asegurador, podemos concluir que ella debe comprender, tanto el daño que la fruta experimentó en sus atributos materializado en la disminución de precio de venta según condiciones ordinarias de mercado y los daños incidentales en que incurrió en observancia de las obligaciones que el propio contrato de seguro le impuso, conservando las mercaderías y minimizando los daños del siniestro. Cualquiera otra pérdida que pueda ser calificada de consecuencial debe ser descartada.

A modo de conclusión, la fijación del contenido de la indemnización que representa el objeto de la obligación del asegurador queda sometida primeramente a las estipulaciones de las partes, en especial aquellas de inclusión de pérdidas más allá del mínimo legal -lucros cesantes-y, también, las exclusiones.

\section{El arbitraje como forma de resolución de conflictos en materia de seguros}

El comercio marítimo es una materia comúnmente sometida a arbitraje en el contexto internacional. En Chile, el legislador plantea el mecanismo arbitral en Derecho marítimo como principio general, mas no con el carácter de forzoso, por cuanto si bien el art. 1203 señala que el conocimiento de toda controversia que derive de hechos, actos o contratos a que dé lugar el comercio marítimo o la navegación, incluidos los seguros marítimos de cualquier clase la expresión será sometido a arbitraje, sin embargo, luego señala una serie de excepciones al referido postulado que desnaturaliza la utilización de este verbo. Así, el inciso segundo de esta disposición señala que lo dispuesto en el inciso anterior 
no será aplicable en los siguientes casos: " $1^{\circ}$. Cuando las partes o interesados expresen su voluntad de someterse a la jurisdicción ordinaria, sea en el mismo acto o contrato que origine la controversia, por acuerdo que conste por escrito, anterior a la iniciación del juicio" ${ }^{\prime \prime 0}$.

De ello se desprende que la obligatoriedad legal de este arbitraje se da sólo cuando las partes nada hubieren señalado sobre la forma de resolución de conflictos y, por supuesto, cuando hubieren acordado este mecanismo expresamente, pero no cuando las partes hubieren acordado que será la justicia ordinaria la que deberá conocer de tales controversias. Tal acuerdo podrá arribarse por las partes ya sea en el momento de constituir el contrato o bien en un momento posterior, siempre y cuando cumpla la formalidad de hacerse por escrito y con la temporalidad de realizarse antes del inicio del juicio arbitral ${ }^{61}$.

En segundo lugar, continúa el precepto en estudio, se excluye esta obligatoriedad de someter el litigio a un arbitraje: " $2^{\circ}$. Cuando se trate de perseguir responsabilidades de orden penal que pudieren originarse en los mismos hechos. En este caso, la acción civil podrá entablarse ante el tribunal que conoce del respectivo proceso criminal o ante el tribunal arbitral a que se refiere el inciso primero". Consiste en los casos en que se trata de perseguir responsabilidades de orden penal que pudieren originarse en los mismos hechos. En este caso, la acción civil podrá entablarse ante el tribunal que conoce del respectivo proceso penal o ante el tribunal arbitral a que se refiere el inciso primero. Dado que el legislador no exige una formalidad especial para que las partes puedan realizar tal elección, se entiende que bastará con entablar la correspondiente demanda civil ante el juez penal, sin necesidad que el demandado esté de acuerdo con la decisión de llevar tal controversia ante este tribunal, toda vez que el legislador no exige un acuerdo previo que así lo señale y deja a total discreción del demandante entablar la demanda ante el juez ordinario o ante el juez arbitral.

En tercer lugar, se excepciona de la regla en comento " $3^{\circ}$. Cuando se trate de los juicios que se mencionan en el párrafo $4^{\circ}$ del título IX de la Ley de Navegación, o de aquellos que, en este mismo Libro, tienen señalado un procedimiento especial que deba seguirse ante un tribunal ordinario". En estos casos se trata de la aplicación de un precepto de carácter especial que entrega competencia a tribunales ordinarios que excluyen, por tanto, a la justicia arbitral. Igualmente se excluye de este escenario: " $4^{\circ}$. Cuando se trate del Fisco o de controversias por responsabilidades que se cumplan ante organismos o servicios portuarios o aduaneros de carácter estatal, u obligaciones controladas por

${ }^{60}$ Sobre arbitraje marítimo, véase: VÁsquez (2011); BARROILHet (2008), pp. 55-103.

${ }^{61}$ Se distancia de este modo, del art. 227 del Código Orgánico de Tribunales y del actual art. 543 del Cco., respecto del contrato de seguros en general, que fuerza el sistema arbitral sin ninguna justificación. 
tales entidades". Lo que se explica por el interés público que se ve envuelto en estas contiendas. En todo caso, esta excepción indica que no serán sometidos al arbitraje señalado en esta disposición, es decir, al que se entiende forzoso, pero nada señala sobre la posibilidad de que estos conflictos sean llevados a un arbitraje por vía voluntaria. En tal contexto, habría que aplicar las prohibiciones señaladas en los arts. 229 y 230 en concordancia con lo estipulado en los arts. 357 y 358 del COT, ya que en la medida que se trate de un juicio de hacienda en que deba intervenir el fiscal judicial, no podrán someterse a arbitraje, en todos los demás, no existirá ningún inconveniente de que así se realice si el Estado actúa como un ente privado.

Finalmente se excluyen de esta obligatoriedad " $5^{\circ}$. Cuando la cuantía del juicio no excediere de 5.000 unidades de cuenta y el demandante optare por ejercitar su acción ante la justicia ordinaria". Causal que se explica en el monto de la disputa, de manera que si es menos puede llevarse con total discreción a la justicia ordinaria. Esta norma parece dejar en evidencia una marcada confianza a favor de la justicia arbitral para la resolución de estas materias, a diferencia de la justicia ordinaria donde se visualiza un riesgo mayor, de modo que el legislador sólo permite que aquélla conozca de estas materias cuando las cantidades disputadas no sean muy altas ${ }^{62}$. En virtud de lo anterior, habría que colegir que no rigen cuando las partes hayan expresamente pactado una cláusula arbitral, la fuerza obligatoria emana del referido contrato y no de la ley, de modo que sólo cabría excepcionar su cumplimiento cuando ella fuera ineficaz o nula, por ejemplo, o cuando recayere sobre una materia inarbitrable ${ }^{63}$.

${ }^{62}$ Sobre el carácter estricto de la actividad marítima y la restringida interpretación que ha de darse al art. 1203 del CCo., cabe mencionar una sentencia pronunciada por la CS, en causa "Compañía de Seguros Generales Cruz del Sur S.A. con Puerto de Lirquén S.A.", con fecha 17 de mayo de 2007, que expresó: "Que, en consecuencia, teniendo en consideración que el asunto debatido en este proceso dice relación con la actividad de la demandada en tanto únicamente depositaría de las mercaderías desestibadas, la que no se relaciona con la navegación y el comercio marítimo, no resulta aplicable el artículo 1203 del Código de Comercio y, en razón de ello, es la justicia ordinaria y no la arbitral la Ilamada a conocer de cualquier controversia que se suscite con motivo del cumplimiento o incumplimiento de las obligaciones que derivan del referido contrato. Que, por último, es también pertinente recordar que la regla del artículo 1203 del Código de Comercio, que establece la norma de competencia para los efectos del comercio marítimo o la navegación, entregándole el conocimiento de todas las controversias que se deriven de los hechos, actos o contratos a que éstos den lugar a Jueces árbitros, ha de interpretarse en forma restrictiva, toda vez que la justicia arbitral en nuestro ordenamiento jurídico es excepcional".

${ }^{63}$ A modo de ejemplo, la CS ha excluido del ámbito de acción de este arbitraje, las relaciones derivadas de dicha actividad, pero que entroncan con materias inarbitrables como sucede con los contratos laborales. La sentencia fue dictada con fecha 23 de enero de 2003, en causa "Igor Amado Macaya Ruiz con Pesquera Itata S.A.", y concretamente señaló: "La responsabilidad civil del empleador por los accidentes de trabajo ocurridos a sus trabajadores, debe hacerse efectiva en conformidad a lo 
En cuanto a las normas sobre procedimiento, rige la voluntad de las partes y en su defecto las contenidas en los códigos procesales (art. 1205 CCo). Las facultades del tribunal arbitral están señaladas en el artículo 1206 del citado cuerpo legal, el que señala que sin perjuicio de lo dispuesto en el artículo anterior, el tribunal arbitral u ordinario, a quien corresponda conocer de los asuntos mencionados en el artículo 1203, tendrá las siguientes facultades: $1^{\circ}$ Podrá admitir, a petición de parte, además de los medios probatorios establecidos en el Código de Procedimiento Civil, cualquier otra clase de prueba; $2^{\circ}$ Podrá, en cualquier estado del juicio, decretar de oficio las diligencias probatorias que estime conveniente, con citación de las partes; $3^{\circ}$ Podrá llamar a las partes a su presencia para que reconozcan documentos o instrumentos, justifiquen sus impugnaciones, pudiendo resolver al respecto, sin que ello implique prejuzgamiento en cuanto al asunto principal controvertido, y $4^{\circ}$ Tendrá la facultad de apreciar la prueba de acuerdo con las normas de la sana crítica, debiendo consignar en el fallo los fundamentos de dicha apreciación.

Por otra parte se plantea en este tipo de juicios una excepción a las normas generales, por cuanto se admiten plenamente las medidas prejudiciales aun cuando a la fecha de su solicitud el tribunal arbitral no esté constituido (art. 1207 CCo). En concreto, el art. 1207 CCo señala: "Cuando se soliciten medidas prejudiciales, sean preparatorias, precautorias o probatorias, o retenciones especiales, antes de estar constituido el tribunal arbitral, el interesado podrá ocurrir ante el juzgado competente en materia civil que estuviere de turno o ante el tribunal al que especialmente asignen competencia normas de este Libro. Lo anterior, sin perjuicio de la prosecución del pleito ante el tribunal arbitral previamente designado o que deba designarse para conocer de la controversia, si las partes no hubieren optado por la jurisdicción ordinaria".

El perfeccionamiento del contrato de seguro marítimo, según dispone el art. 1173 del CCo., servirá para justificar el momento y los términos del acuerdo, la propuesta, la nota de cobertura o cualquier otro documento que se utilice entre asegurados, corredores y aseguradores. Tendrá también el mérito de póliza la nota de cobertura u otro documento que acostumbren utilizar los aseguradores para señalar las condiciones de los seguros que hubieren sido aceptados por ellos. Igualmente, es dable considerar que en el comercio marítimo se atribuye a la expresión "por escrito" un significado más amplio que la general,

establecido en el Código del Trabajo, que es ley especial sobre la materia y prima sobre el derecho común, conforme lo prescriben los artículos $4^{\circ}$ y 13 del Código Civil. Resulta en consecuencia, que corresponde al Juzgado del Trabajo conocer de la demanda de indemnización de perjuicios y no a un Tribunal Arbitral, según alega la demandada, fundado en el artículo 1203 inciso $1^{\circ}$ de Código de Comercio por tratarse de una relación de naturaleza naviera, por lo que procede desechar el incidente de incompetencia absoluta formulado por la demandada". 
incluyendo en ella al telegrama, télex u otros medios que registren o repitan lo estampado en instrumentos o aparatos diseñados para las comunicaciones de las partes (fax, correo electrónico, etc.). El resguardo de los estándares de buena fe es indispensable para el adecuado funcionamiento de la justicia comercial marítima. Ello es especialmente relevante cuando se trata de aplicar ciertas instituciones nuevas, incorporadas por el Libro III del Código de Comercio, que tienen un marcado componente de informalismo y predominio de la buena fe. A manera de ejemplo, se pueden citar dos gestiones de naturaleza probatoria a las que se refieren los artículos 1208 (comprobación de hechos) y 1209 (prueba extrajudicial).

\section{Conclusiones}

1. La regla contractual en el seguro marítimo se construye a partir de las normas imperativas de su régimen legal especial, el acuerdo entre las partes y a falta de estipulaciones expresas, por las normas que conforman el referido régimen; $y$, en caso de laguna en este último, por las generales de los artículos 512 y siguientes del Código de Comercio, que constituyen el derecho común y supletorio en la materia. Adicionalmente, en lo no previsto por las partes y el Código de Comercio, este contrato se rige por las reglas generales del Libro IV del Código Civil.

2. Los elementos de la esencia de este contrato son el riesgo y la prima por su transferencia; y uno de sus efectos esenciales -pero eventual para el caso que ocurra el riesgo previsto- es la obligación de indemnizar al asegurado según lo pactado aquellos daños causalmente vinculados con tal ocurrencia.

3. La obligación de indemnización nace como consecuencia de la concurrencia de ciertas condiciones y sólo comprende aquellos daños causalmente vinculados con el riesgo asegurado y no excluidos por ley o voluntad de las partes.

4. En el contrato de seguro la indemnización no constituye manifestación de la responsabilidad civil, sino con su efecto y se traduce en una obligación dineraria de cuantía indeterminada cuya fijación corresponde al liquidador designado o, en caso de desacuerdo entre las partes, por el juez o el árbitro que conozca de correspondiente demanda.

5. Si el asegurado incurre en incumplimiento contractual, negándose a pagar la indemnización o pagándola parcialmente, al asegurado le asiste el derecho a exigir la ejecución de lo pactado por medio de la pretensión de cumplimiento específico, sin perjuicio de la indemnización de los daños subsecuentes por la infracción contractual.

6. Para develar el contenido concreto de la obligación del asegurador resulta de utilidad trasladar al contrato de seguro la tipología de daños propia 
de la responsabilidad civil contractual que considera tres clases o especies de daños: los que inciden en el objeto asegurado, los costos incidentales por la observancia del deber de mitigar las pérdidas y de conservación del referido objeto; y los consecuenciales o subsecuentes que exceden del valor del objeto asegurado y presuponen la lesión del interés de integridad patrimonial y personal del asegurado, como es el caso del lucro cesante. La indemnización objeto del seguro, sin perjuicio de las limitaciones y/o exclusiones convencionales, comprende naturalmente los daños al objeto asegurado y los incidentales, no así los consecuenciales. La inclusión de esta última especie de daño requiere de pacto o estipulación expresa entre las partes.

7. La resolución de los conflictos que emergen del seguro marítimo, son llevados normalmente a sede arbitral, sin Ilegar a ser esta forma de resolución obligatoria o forzada. Su conformación presenta rasgos particulares que deben considerarse a estos efectos.

\section{BiBLIOGRAFíA CITADA}

Arellano Iturriaga, Sergio (2013): La ley del seguro (Santiago, LegalPublishing). Contreras Strauch, Osvaldo (2014): Derecho de Seguros (Santiago, Thomson Reuters).

Baeza Pinto, Sergio (1994): El seguro (Santiago, Editorial Jurídica de Chile).

Ballester Grau, Juan (1997): La liquidación del siniestro en el seguro de daños (Valencia, Tirant Lo Blanch).

BarRientos Zamorano, Marcelo (2015 a): "Nuevos deberes precontractuales de información en los certificados de cobertura provisorio, definitivo y la propuesta del contrato de seguro", en Revista de Derecho Universidad Católica del Norte (Vol. № 21, № 1), pp. 65-104.

BarRientos Zamorano, Marcelo (2015 b): "El deber precontractual de información en el contrato de seguro, un producto financiero y de consumo. Estudio de sus fuentes", en Revista Chilena de Derecho (Vol. 42, No 2), pp. 423-451.

Barrientos Zamorano, Marcelo, (2015 c): "Art. 529. Obligación del asegurado El deber precontractual de información", en El contrato de seguro. Comentarios al Título VIII, Libro II del Código de Comercio chileno (Santiago, Ed. Thomson Reuters), pp. 123-126.

Barros Bourie, Enrique (2007): Tratado de responsabilidad extracontractual (Santiago, Ed. Jurídica).

Barrollhet Acevedo, Claudio (2007): Derecho de seguro marítimo (Santiago, Ed. Librotecnia). 
Barroilhet Acevedo, Claudio (2008): "Arbitraje marítimo chileno", en Análisis retrospectivo de los 30 años de navegación y los 20 años del Libro III del Código de Comercio Chileno (Santiago, Ed. Librotecnia), pp. 33-48.

Berccovitz Rodríguez-Cano, Alberto (Director) (2013): Contratos mercantiles (Cizur Menor, Thomson Reuters-Aranzadi).

Broseta Pont, Manuel (1991): Manual de Derecho mercantil (Madrid, Tecnos).

De la MAZA GaZmurı, Íñigo (2015): "La conformidad de la cosa vendida: adecuación material", en Revista de Derecho de la Universidad Austral de Chile (Vol. 28, No 1), pp. 79-100.

De Verda y Beamonte, José Ramón (2009): Saneamiento por vicios ocultos. Las acciones edilicias (Navarra, Aranzadi).

Díez-PICAzo y Ponce de León, Luis (2008): Fundamentos de derecho civil patrimonial: las relaciones obligatorias (Madrid, Civitas).

Díez-Picazo, Luis; Roca Trías, María; y Morales Moreno, Antonio (2002): Los principios del Derecho europeo de contratos (Madrid, Civitas).

Díez-PICAZO, Luis (2008): Fundamentos del derecho civil patrimonial (Navarra, Civitas).

Domínguez Águila, Ramón (2005): "Notas sobre el deber de minimizar el daño", en Revista Chilena de Derecho Privado (Año 4, № 5), pp. 73-95.

Edwin Peel y G.H. Treitel (2011): The Law of Contract (Londres, Sweet \& Maxwell).

Farnsworth E., Allan (2004): Contracts (New York, Aspen).

Lagos Villarreal, Osvaldo (2015): "Art. 524. Obligaciones del asegurado", en El contrato de seguro, Comentarios al Título VIII, Libro II del Código de Comercio chileno (Santiago, Ed. Thomson Reuters), pp. 90-94.

López Santa María, Jorge (2010): Los contratos, Parte General, $5^{\mathrm{a}}$ ed. Actualizada por ElorRIaGa de BonIs, Fabián (Santiago, Thomson Reuters).

Morales Moreno, Antonio (2010): Incumplimiento del contrato y lucro cesante (Navarra, Civitas).

Morales Moreno, Antonio (2011): "Indemnización del lucro cesante en caso de incumplimiento de contrato", en Incumplimiento contractual, Nuevas Perspectivas (Santiago, Universidad Diego Portales).

Morales Moreno, Antonio; De la Maza Gazmuri, Íñigo; y Vidal Olivares, Álvaro (2014): "Incumplimiento por inhabilidad del objeto e indemnización de daños. Comentario de la sentencia de la Corte Suprema de 31 de octubre de 2012", en Revista Chilena de Derecho, (Vol. 41, № 3), pp. 1155-1178.

Pantaleón Prieto, Fernando (1998): "Artículo 74 CISG", en La compraventa internacional de mercaderías, Comentario de la Convención de Viena, en Díez-Picazo y Ponce de León, Luis (Madrid, Civitas). 
Pizarro Wilson, Carlos (2013): "Contra el fatalismo del perjuicio. A propósito del deber de mitigar el daño", en Revista de Derecho de la Pontificia Universidad Católica de Valparaíso, (Vol. 41, № 2).

Ríos Ossa, Roberto (2015 a): "Art. 513 t)", en "El contrato de seguro. Comentarios al título VII, Libro Il del Código de Comercio" (Santiago, Ed. Thomson Reuters).

Ríos Ossa, Roberto (2015 b): "Carácter imperativo de las normas. Art. 542", en El contrato de seguro. Comentarios al Título VIII, Libro II del Código de Comercio Chileno (Santiago, Ed. Thomson Reuters).

SAn Martín Neira, Lilian (2012): La carga del perjudicado de evitar o mitigar el daño, Estudio histórico-comparado (Bogotá, Universidad de Externado).

SánChez CAlero, Fernando (2009): Instituciones de Derecho comercial (Navarra, Aranzadi-Thomson Reuters).

StolL, Hans (1998): Commentary on the UN Convention the International sale of Goods (Oxford, GISG).

Veiga Copo, Abel (2014): Tratado del Contrato de Seguro, $3^{a}$ edición (Navarra, Civitas), Tomo I.

VÁsquez Palma, María Fernanda (2011): Arbitraje en Chile. Análisis crítico de su normativa y jurisprudencia (Santiago, Ed. LegalPublishing).

Vidal Olivares, Álvaro (2000): "La construcción de la regla contractual en el derecho civil de los contratos", en Revista de Derecho de la Pontificia Universidad Católica de Valparaíso (№ 21), pp. 209-227.

Vidal Olivares, Álvaro (2005): "La gestión razonable de los efectos del incumplimiento en la compraventa internacional", en Revista de Derecho de la Universidad Austral de Chile (Vol. 18, № 2), pp. 55-81.

VidAl Olivares, Álvaro (2006): La protección del comprador, régimen de la Convención de Viena y su contraste con el Código Civil (Valparaíso, Ediciones Universitarias, PUCV).

Vidal Olivares, Álvaro, (2008): "La carga de mitigar las pérdidas del acreedor, en Guzmán Brito, Alejandro (Editor científico), Estudios de Derecho Civil, (Santiago, LegalPublishing), Tomo III.

\section{NORMAS JURÍDICAS CITADAS}

I. Código de Comercio, Diario Oficial, 23 de noviembre de 1865.

II. Decreto Supremo № 1.055, Superintendencia de Valores y Seguros, Diario Oficial, 29 de diciembre de 2012.

III. Decreto con Fuerza de Ley No 251, Diario Oficial, 22 de mayo de 1931.

IV. Ley No 20.667, Diario Oficial, 9 de mayo de 2013. 